\title{
Bending Moment Characteristics of Hard Roof before First Breaking of Roof Beam Considering Coal Seam Hardening
}

\author{
Shitan Gu, ${ }^{1,2}$ Bangyou Jiang $\mathbb{D D}^{1,2}{ }^{1,}$ Yue Pan, ${ }^{3}$ and Zheng Liu ${ }^{1}$ \\ ${ }^{1}$ State Key Laboratory of Mining Disaster Prevention and Control Co-Founded by Shandong Province and \\ the Ministry of Science and Technology, Shandong University of Science and Technology, Qingdao 266590, China \\ ${ }^{2}$ National Demonstration Center for Experimental Mining Engineering Education, \\ Shandong University of Science and Technology, Qingdao 266590, China \\ ${ }^{3}$ School of Civil Engineering, Qingdao Technological University, Qingdao 266520, China \\ Correspondence should be addressed to Bangyou Jiang; jiangbangyou123@163.com
}

Received 4 March 2018; Accepted 4 June 2018; Published 10 July 2018

Academic Editor: Salvatore Russo

Copyright (C) 2018 Shitan Gu et al. This is an open access article distributed under the Creative Commons Attribution License, which permits unrestricted use, distribution, and reproduction in any medium, provided the original work is properly cited.

\begin{abstract}
The mechanical properties of a coal seam affect the distribution of support pressure. Considering the strain hardening effect of coal seam, the support pressure relationship of three zones - softened, hardened, and elastic - of a coal seam with regard to a hard roof is proposed, and methods to determine an approximate expression for the support pressure of hardened zone of coal seam, the range of hardened zone, and the corresponding peak values of support pressure are provided. The deflection equations of a hard roof under three different support pressure relationships of coal seam before the first breaking were theoretically derived, and all the relevant integration constants were determined. Numerical examples of two cases are provided for calculating the bending moment of a hard roof and the support pressure of a coal seam. The analysis shows that as the working face advances, the maximum support pressure increases, the residual strength of coal seam at coal wall decreases, the overall deflection of roof gradually increases, the maximum bending moment of roof in the front of coal wall increases, and the advanced distance of roof bending moment peak gradually increases. As the depth of softened zone of coal seam increases, the similar conclusion is obtained, and the advanced distance of the roof bending moment peak increases at a relatively fast speed. Because the bending moment peak of hard roof is located near the support pressure peak in the softened zone of coal seam, the depth of softened zone of coal seam significantly affects the advanced distance of the bending moment peak of a roof. The actual advanced fracture distances of hard roof are distributed in a relatively broad range. The results indicate that there is a "large and long" type advanced fracture distance occurring in the actual stope. With the same overlying load and stope parameter conditions, the maximum support pressures of support roof in softened, hardened, and elastic zones considering a hardened coal seam are smaller than those in softened and elastic zones without hardening. However, the plumpness in front of the peak of the former support pressure curve is superior to that of the latter, and both the bending moment peak value and the advanced distance of bending moment peak of the former are higher than those of the latter.
\end{abstract}

\section{Introduction}

In the early stage of working face mining, a large area of hard roof overhangs in the goaf. When the critical hanging roof distance is reached, the hard roof starts to rupture in front of the coal wall. For a hard roof with advanced fracture, when the working face advances to below the roof fracture line, if the supporting resistance of frame and friction between seams are insufficient, the roof easily subsides in a stepped style, causing collapse accidents under pressure and even rock burst disasters. Many studies have been conducted on the deformation, law of motion, and fracture of a hard roof under the overlying load by field observation, similar material simulation, numerical simulation, and theoretical analysis [1-14]. Qian et al. [15, 16], Miao et al. [17], and Li et al. [18] analyzed a hard roof by assuming the support pressure relationship between coal seam and immediate roof as an elastic foundation and obtained some basic results such as the deflection solution for a hard roof and the maximum bending moment in the front of a coal wall and for an advanced roof fracture. 
Studies on support pressure showed that the coal seam near the coal wall is softened before applying pressure; the coal seam is in a yielding and softened state. Therefore, the assumption that all the support pressure relationship of a coal seam on a hard roof is elastic foundation is far from the reality. Peng [19] reported that a coal seam is in a softened state from the coal wall to the support pressure peak, and the coal seam is in an elastic state ahead of the support pressure peak. Based on this understanding, Pan et al. [20] analyzed the bending moments of a supporting hard roof in the softened and elastic zones; they found that when the residual strength of a coal seam at the coal wall is sufficiently low, the maximum bending moment and advanced distance of bending moment peak of a support roof in the softened and elastic zones under the same overlying load are exponentially larger than the corresponding values of a completely elastic foundation support roof.

Figure 1 shows the distribution diagram of measured support pressures obtained by Shao et al. [21] for the third mining area of the west wing of Xieqiao Coal Mine in Huainan city. The curve section at the first measuring point ahead of support pressure peak is convex, while that ahead of the second measuring point is concave. The intermediate point between the convex and concave sections is the inflection point of curve. The support pressure ahead of the inflection point is relatively small, and the coal seam is in an elastic state. For the convex section between the inflection point and pressure peak, the coal seam has the hardening state (unlike elastic characteristics). The coal seam between the pressure peak and coal wall has the yield softening state. Because of the difference in the mechanical properties of coal seam, the coal seam in Figure 1 shows three different support pressure relationships for the roof, i.e., softened zone, hardened zone, and elastic zone, bounded by the support pressure peak and inflection point of curve, consistent with the division of four zones-flow zone, softened zone, hardened zone, and elastic zone-for the support pressure relationship of the immediate roof of coal seam on the main roof proposed by $\mathrm{He}$ et al. [22].

Figure 2 shows the schematic diagram of support pressure of coal seam when the working face advances in a phase before the breaking of hard roof shown by Shao et al. [23]. $P$, $S$, and $D$ in Figure 2 are advanced support pressure, advanced distance, and load of powered support of working face, respectively. The distance of overhanging roof and support pressure peak increases with the advance of working face. In fact, with the increase in hanging roof distance, the total load caused by the overlying strata on the coal seam increases, the fracture state of coal seam at coal wall becomes severe, the residual strength decreases, and the depth of softened zone increases. A change in support pressure changes the bending moment and advanced distance of bending moment peak for a hard roof.

The mechanical properties of a coal seam in different mines are different; such a difference causes difference in the distribution pattern of support pressure of coal seam. The softened, hardened, and elastic three-zone support pressure relationship of hardening effect of coal seam can be better understood from the softened and hardened two-zone

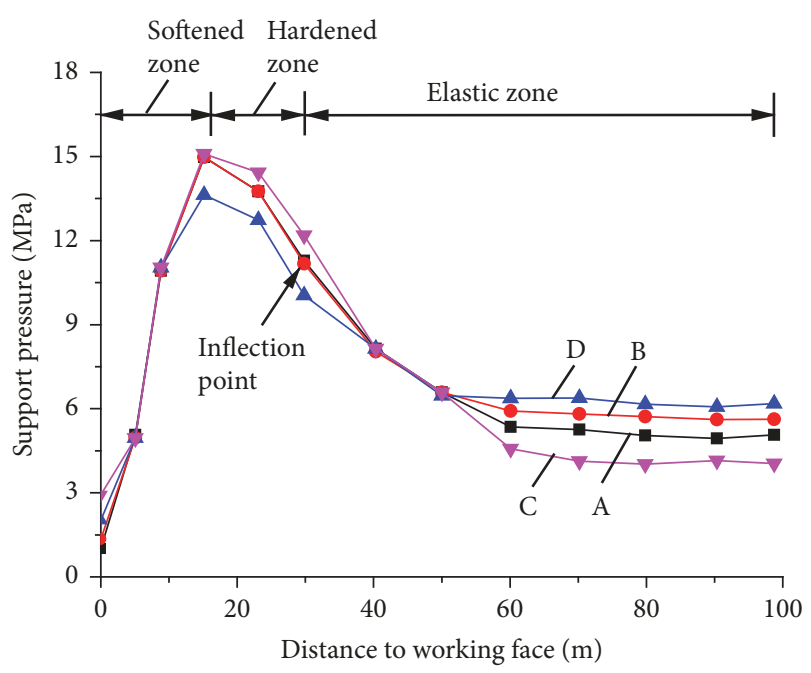

FIGURE 1: Distribution picture of support pressure of each measured points [21].

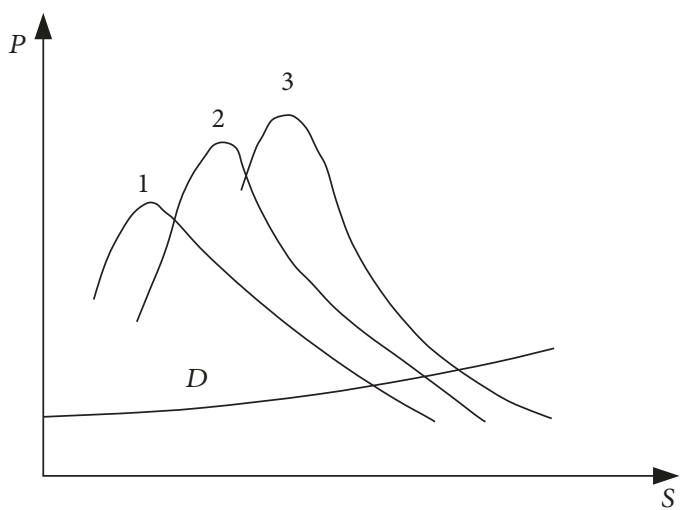

FIGURE 2: Support pressure of coal seam when working face advancing [23].

support pressure relationship of coal seam. The consideration of depth variation of hardened and softened zones of coal seam significantly affects the maximum bending moment and advanced distance of bending moment peak. Based on previous study [20], the relationship between a coal seam and roof was regarded as softened, hardened, and elastic three-zone support in this study. Focusing on a phase in which the working face advances and the hanging roof distance increases before the first breaking and the case in which the depth of softened zone of coal seam varies, the bending moment of hard roof was theoretically analyzed. The numerical example was provided by Matlab software, and the relevant values under the same overlying load conditions were compared with those only considering the softened and elastic support of coal seam for a hard roof. The results can lead to a better understanding of the variations in bending moment, advanced distance of bending moment peak, and deflection of hard roof when the hanging roof distance and depth of softened zone of coal seam increase. 


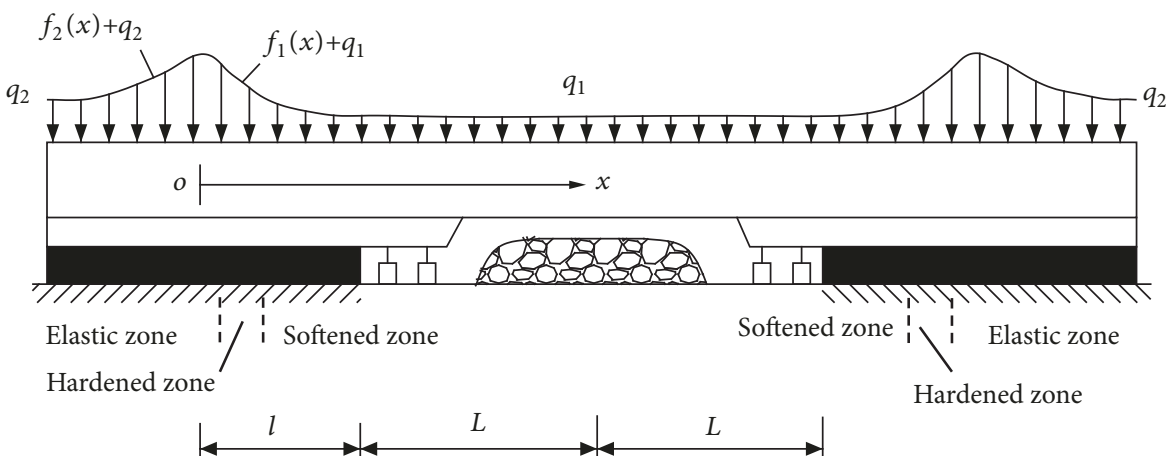

FIGURE 3: Surrounding rock constitution and load state of hard roof before first breaking.

\section{Analytical Model}

2.1. Analytical Model and Overlying Load Expression of Roof. Generally, the working face of a stope is relatively long. Therefore, the softened zone of a coal seam in the middle part of working face has the maximum depth and the largest bending moment of roof, and the fracture comes first. Usually, the bending moment characteristics of a roof in the middle part of a stope were studied using the strata structure of unit width - the system of a rock beam [10, 15-18] along the advancing direction in the middle part of a stope. Qian et al. [15] found it similar to the support pressure of coal seam: the hard roof in front of the coal wall bears a supercharged load of uplift distribution in addition to the average load, except that the uplift part is relatively flat and the supercharged load peak is located ahead of coal seam support pressure peak. Thus, the strata structure of unit width before the first breaking of hard roof can be determined by considering three support pressure relationships of coal seam, i.e., elastic, hardened, and softened, as shown in Figure 3. To simplify analysis, both sides of rock beam were assumed to have supports and both the structure and the loads in the picture were assumed to be symmetric with respect to the midspan of goaf. According to structural mechanics, the midspan crosssectional shear force of rock beam in a symmetric system is 0 , i.e., $Q(l+L)=0$. The angle of the midspan crosssection of rock beam is 0 , i.e., $y_{1}^{\prime}(L+l)=0$. Hence, the semistructure, i.e., the model in Figure 4 whose right end is a directed support, can be used to analyze the bending moment characteristics of the middle part of hard roof before the first breaking.

The origin of the coordinate $o$ in Figure 4 is located beneath the supercharged load peak of rock beam. The distance from the point $o$ to the coal wall is $l$, and its distances to the hardened and softened zones of coal seam are $l_{4}$ and $l_{3}$, respectively. $l_{4}$ is the location coordinate of the inflection point on the support pressure curve of coal seam. The support pressures of the softened and hardened zones of coal seam on rock beam are denoted by $f_{3}(x)$ and $F_{4}(x)$, respectively. The length of support is $L_{k}$, and the support resistances are $p_{o}$ and $p_{k}$. The maximum supercharged load above the rock beam is higher than the evenly distributed load from the distant position, and the rock beam load far from load peak tends

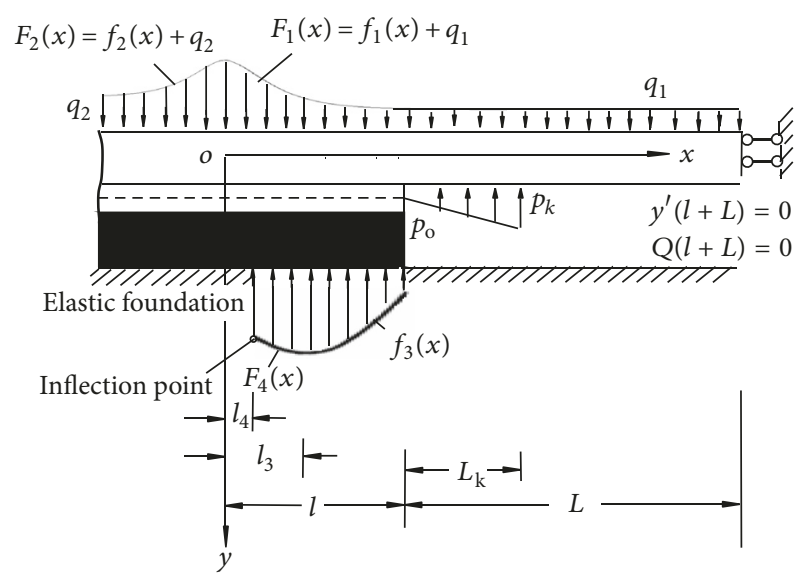

FIGURE 4: Semiconstitution model of hard roof.

towards evenly distributed forces $q_{1}$ and $q_{2}$. The following expressions can be used:

$$
\begin{array}{r}
F_{1}(x)=q_{1}+f_{1}(x)=q_{1}+k_{1}\left(x+x_{\mathrm{c} 1}\right) \mathrm{e}^{-\left(x+x_{\mathrm{c} 1}\right) / x_{\mathrm{c} 1},} \\
(0 \leq x \leq l+L) \\
F_{2}(x)=q_{2}+f_{2}(x)=q_{2}+k_{2}\left(x_{\mathrm{c} 2}-x\right) \mathrm{e}^{\left(x-x_{\mathrm{c} 2}\right) / x_{\mathrm{c} 2},} \\
(x \leq 0)
\end{array}
$$

to simulate the evenly distributed load and uplift-distributed load on rock beam ahead of and after supercharged load peak in Figure 4, where

$$
\begin{aligned}
& k_{1}=\frac{f_{\mathrm{c} 1} \mathrm{e}}{x_{\mathrm{c} 1}}, \\
& k_{2}=\frac{f_{\mathrm{c} 2} \mathrm{e}}{x_{\mathrm{c} 2}}
\end{aligned}
$$

In (3), $f_{\mathrm{c} 1}$ and $f_{\mathrm{c} 2}$ are the peak values of $f_{1}(x)$ and $f_{2}(x)$, respectively, whereas $x_{\mathrm{c} 1}$ and $x_{\mathrm{c} 2}$ are the scale parameters. The value of supercharged load peak can be adjusted by changing $f_{\mathrm{c} 1}$ and $f_{\mathrm{c} 2}$, and, in the process of $x \longrightarrow \pm \infty$, the speed of $f_{1}(x) \longrightarrow 0$ and $f_{2}(x) \longrightarrow 0$ can be adjusted by varying $x_{\mathrm{cl}}$ and $x_{\mathrm{c} 2}$. 


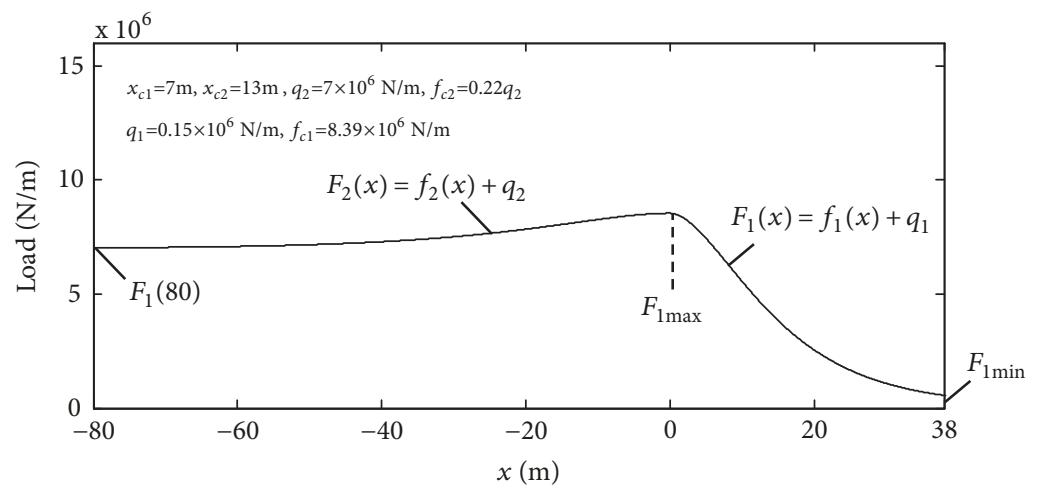

FIGURE 5: Load on roof in analysis and calculation.

The relationship between $f_{\mathrm{c} 1}, f_{\mathrm{c} 2}$, and even loads on the beam $q_{1}, q_{2}$ is defined as follows:

$$
\begin{aligned}
q_{1}+f_{\mathrm{c} 1} & =q_{2}+f_{\mathrm{c} 2}, \\
\text { or } f_{\mathrm{c} 1}-f_{\mathrm{c} 2} & =q_{2}-q_{1}
\end{aligned}
$$

Equation (4) ensures smooth and continuous supercharged load peaks in Figures 2 and 4.

In the case where the buried depth is $\sim 350 \mathrm{~m}$, the volumetric weight of overlying rock and soil mass is $\gamma=$ $20000 \mathrm{~N} / \mathrm{m}^{3}$ and the average load on beam is $q_{2}=\gamma H=$ $7 \mathrm{MN} / \mathrm{m}$. If $f_{\mathrm{c} 2}=0.22 q_{2}$, roof thickness $h=6 \mathrm{~m}$ and volumetric weight $\gamma^{\prime}=25000 \mathrm{~N} / \mathrm{m}^{3}$ according to literature [26], $q_{1}=\gamma^{\prime} h=0.15 \mathrm{MN} / \mathrm{m}$. Equation (4) shows that $f_{\mathrm{cl}}=$ $q_{2}+f_{\mathrm{c} 2}-q_{1}=8.39 \mathrm{MN} / \mathrm{m}$. If $l=18 \mathrm{~m}$ in Figure 4 , the hanging roof distance of hard roof is $L=20 \mathrm{~m}$. The roof load slowly decreases ahead of supercharged load peak but becomes fast after the supercharged load peak in Figure 4. Therefore, the scale parameters in (3) are assigned as $x_{\mathrm{c} 2}=13 \mathrm{~m}$ and $x_{\mathrm{c} 1}=$ $8 \mathrm{~m}$. Based on the above values and according to (1)-(3), the load distribution on rock beam from $-100 \mathrm{~m}$ to $38 \mathrm{~m}$ was plotted by Matlab and shown in Figure 5 .

The load intensity $100 \mathrm{~m}$ ahead in Figure 5 is denoted by $F_{1}(100) \longrightarrow q_{2}=7 \mathrm{MN} / \mathrm{m}$. The supercharged load peak is located at $x=0$. The load curve is smooth and continuous, and $F_{1 \max } / q_{2}=1.22$. The midspan load intensity of rock beam is $F_{1 \mathrm{~min}}=0.58 \mathrm{MN} / \mathrm{m}\left(\sim 3.78 q_{1}\right.$, i.e., 3.78 times of the roof weight), which is far less than the mean load on beam $q_{2}=7 \mathrm{MN} / \mathrm{m}$. Figure 6 shows the results of finite element analysis conducted by Qian et al. [15] for the distribution pattern of overlying load of the key overlying strata $\left(\sum h_{3}=\right.$ $0 \mathrm{~m}$ is equivalent to $150 \mathrm{~m}$ ). Compared with Figure 6, the load curve shown in Figure 5 can better simulate the roof load curve with a buried depth of $350 \mathrm{~m}$.

2.2. Expressions of Support Pressures in Softened and Hardened Zones of Coal Seam. For the coordinate in Figure 4, the support pressure in the softened zone of coal seam can be expressed as follows:

$$
\begin{aligned}
f_{3}(x) & =\frac{f_{c 3} \mathrm{e}}{x_{c 3}}\left[\left(l_{3}+x_{c 3}\right)-x\right] \mathrm{e}^{\left(x-l_{3}-x_{c 3}\right) / x_{c 3}} \\
& =k_{3}\left[\left(l_{3}+x_{c 3}\right)-x\right] \mathrm{e}^{\left(x-l_{3}-x_{c 3}\right) / x_{c 3}}, \quad\left(l_{3} \leq x \leq l\right)
\end{aligned}
$$

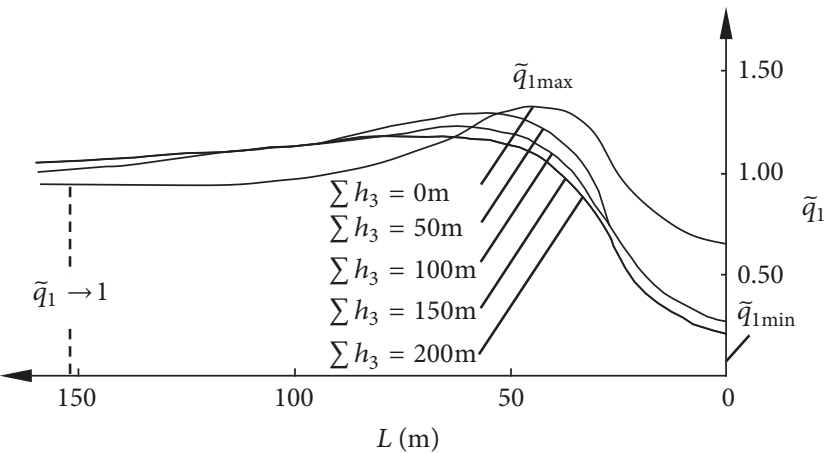

FIGURE 6: Relation of loads on the roof and buried depth [15].

In (5), when $x=l_{3}$, the maximum support pressure of coal seam is located at $f_{3}\left(l_{3}\right)=f_{\mathrm{c} 3}$ and $x_{\mathrm{c} 3}$ is the scale parameter for $f_{3}(x)$. Equation (5) shows that

$$
k_{3}=\frac{f_{\mathrm{c} 3} \mathrm{e}}{x_{\mathrm{c} 3}}
$$

In (5), if $f_{c 3}$ is large, the support pressure intensity in the softened zone of coal seam is also large.

The support pressure in the hardened zone of coal seam $\left[l_{4}, l_{3}\right]$ can be expressed as follows:

$$
\begin{aligned}
F_{4}(x) & =q_{2}+f_{4}(x) \\
& =q_{2}+k_{4}\left[\left(l_{3}+x_{c 4}\right)-x\right] \mathrm{e}^{\left(x-l_{3}-x_{c 4}\right) / x_{c 4}}, \\
& \left(0<l_{4} \leq x \leq l_{3}\right)
\end{aligned}
$$

where $x_{c 4}$ is the scale parameter for $f_{4}(x)$. In $(7), F_{4}(x)$ tends to the mean load $q_{2}$ when $x \longrightarrow-\infty$, where

$$
k_{4}=\frac{f_{\mathrm{c} 4} \mathrm{e}}{x_{\mathrm{c} 4}}
$$

By taking the derivative twice with respect to $f_{4}(x)$ in (7) and letting it be 0 , the relationship among $l_{4}, l_{3}$, and $x_{c 4}$ at the inflection point on support pressure curve of coal seam can be expressed as follows:

$$
l_{4}=l_{3}-x_{\mathrm{c} 4}
$$




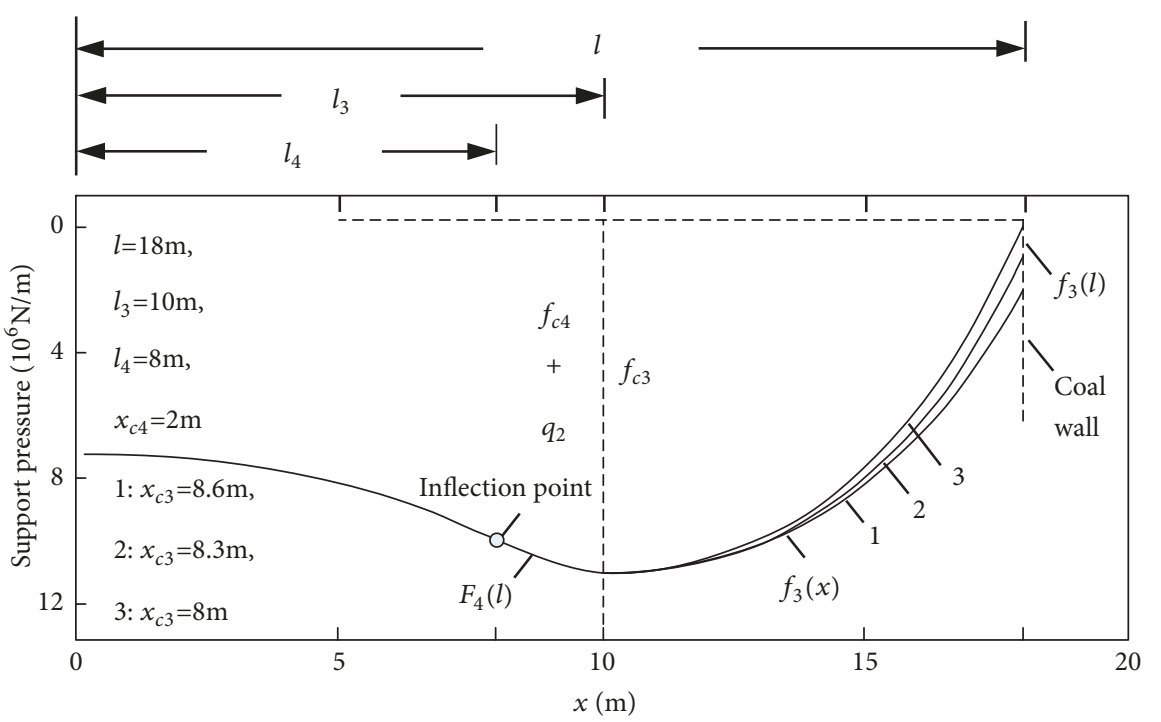

FIGURE 7: Schematic drawings of support pressure to roof in softened zone and hardened zone of coal seam.

In (7), $F_{4}\left(l_{3}\right)=q_{2}+f_{c 4}$ when the maximum support pressure curve of coal seam is $x=l_{3}$, where $f_{c 4}$ is the maximum $f_{4}(x)$. Because $f_{4}^{\prime}\left(l_{3}\right)=0$ and $F_{4}^{\prime}\left(l_{3}\right)=0$, let $F_{4}\left(l_{3}\right)=f_{\mathrm{c} 3}$. The support pressure curve of coal seam is then smoothly connected at $x=l_{3}$, and thus

$$
f_{\mathrm{c} 3}=f_{\mathrm{c} 4}+q_{2}
$$

For $l_{3}=10 \mathrm{~m}$ and $x_{\mathrm{c} 4}=2 \mathrm{~m}$, the inflection point location of support pressure curve of coal seam $l_{4}=8 \mathrm{~m}$ can be obtained using (9). Suppose $f_{\mathrm{c} 3}=11 \mathrm{MN} / \mathrm{m}$, with respect to $q_{2}=7 \mathrm{MN} / \mathrm{m}$ and $x_{\mathrm{c} 3}=8.6,8.3$, and $8 \mathrm{~m} q_{2}=7 \mathrm{MN} / \mathrm{m}$ and according to (5), (7), and (10), the support pressure curve $F_{4}(x)$ (x is the $[8,10] \mathrm{m}$ section) for the hardened zone of coal seam when $l_{4}=8 \mathrm{~m}$ and $x_{\mathrm{c} 4}=2 \mathrm{~m}$ and the support pressure curve $f_{3}(x)$ ( $\mathrm{x}$ is the $[10,18] \mathrm{m}$ section) for the softened zone of coal seam when $l_{3}=10 \mathrm{~m}$ and $x_{\mathrm{c} 3}=8.6,8.3$, and $8 \mathrm{~m}$ were plotted by Matlab, as shown by curves 1, 2, and 3 in Figure 7. A horizontal tangent line is located at $l_{3}=10 \mathrm{~m}$ on the support pressure curves. $f_{3}(l)$ is the residual strength of coal seam at coal wall. $f_{3}(l)$ can be varied in the range of [0 0.8] $f_{\mathrm{c} 3}$ by adjusting $x_{\mathrm{c} 3}$. The curves shown in Figure 7 can better simulate the support pressures of coal seam from the inflection point to the coal wall in Figures 1 and 4 . In particular, $f_{\mathrm{c} 3}=11 \mathrm{MN} / \mathrm{m}$ in Figure 7 is manually drawn the schematic diagram, whereas the value of $f_{\mathrm{c} 3}$ in the numerical example was determined according to the method introduced in Section 5 by the varying overlying load corresponding to the increase in the hanging roof distance or the depth of softened zone of coal seam in Figure 4.

\section{Deflection Equations and Continuity Conditions for Various Zones of Rock Beam}

3.1. Deflection Equation of Rock Beam for Elastic Foundation Zone. For the zones $(-\infty, 0]$ and $\left(0, l_{4}\right]$ in Figure 4 , the coal seam is in the elastic state; therefore, the supporting relationship of coal seam on roof in both the zones was treated as elastic foundation. The reaction force of elastic foundation $q_{\mathrm{c}}$ is directly proportional to the displacement of rock beam $y$, i.e., $q_{\mathrm{c}}=-C y$, where $C$ is the elastic foundation constant and the minus represents the opposite direction of reaction force and displacement $y$ (the settlement amount of rock beam). A distributed force $F_{2}(x)=q_{2}+f_{2}(x)$ was applied above the rock beam in zone $(-\infty, 0]$. The deflection of rock beam in this zone was denoted as $y_{2}(x)$. Following Timoshenko [27], the differential equation for the deflection of any infinitesimal segment $\mathrm{d} x$ in zone $(-\infty, 0]$ of a rock beam can be derived as follows:

$$
\begin{array}{r}
E I y_{2}{ }^{(4)}(x)=q_{2}+k_{2}\left(x_{\mathrm{c} 2}-x\right) \mathrm{e}^{\left(x-x_{\mathrm{c} 2}\right) / x_{\mathrm{c} 2}}-C y_{2}(x), \\
(x \leq 0)
\end{array}
$$

where $E$ is the elastic modulus of roof under the condition of plane strain and $I$ is the moment of inertia for the roof with unit width. If $\beta=[C /(4 E I)]^{1 / 4}$, (11) can be expressed as follows:

$$
y_{2}^{(4)}(x)+4 \beta^{4} y_{2}(x)=\frac{q_{2}}{E I}+\frac{k_{2}}{E I}\left(x_{\mathrm{c} 2}-x\right) \mathrm{e}^{\left(x-x_{\mathrm{c} 2}\right) / x_{\mathrm{c} 2}},
$$

$$
(x \leq 0)
$$

For the zone $\left[0, l_{4}\right]$ shown in Figure 4 , the distributed load applied above on the elastic foundation beam is $F_{1}(x)=$ $q_{1}+f_{1}(x)$. The deflection of the rock beam in zone $\left[0, l_{4}\right]$ was denoted as $y_{21}(x)$. Similar to (12), the differential equation for the deflection of any infinitesimal segment $\mathrm{d} x$ in zone $\left[0, l_{4}\right]$ can be derived as follows:

$$
\begin{aligned}
y_{21}{ }^{(4)}(x)+4 \beta^{4} y_{21}(x) \\
=\frac{q_{1}}{E I}+\frac{k_{1}}{E I}\left(x+x_{\mathrm{c} 1}\right) \mathrm{e}^{-\left(x+x_{\mathrm{c} 1}\right) / x_{\mathrm{c} 1}}, \quad\left(0 \leq x \leq l_{4}\right)
\end{aligned}
$$

Because the differential equations for deflections (12) and (13) are identical to that of the corresponding zones 


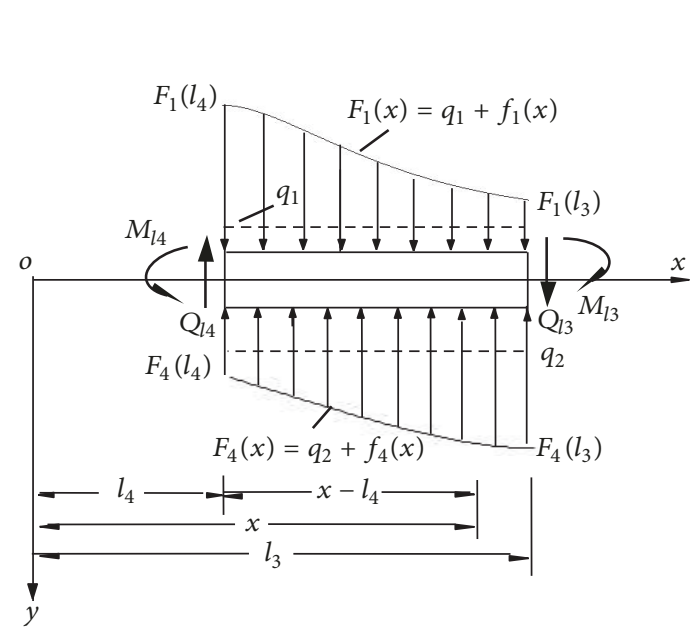

(a)

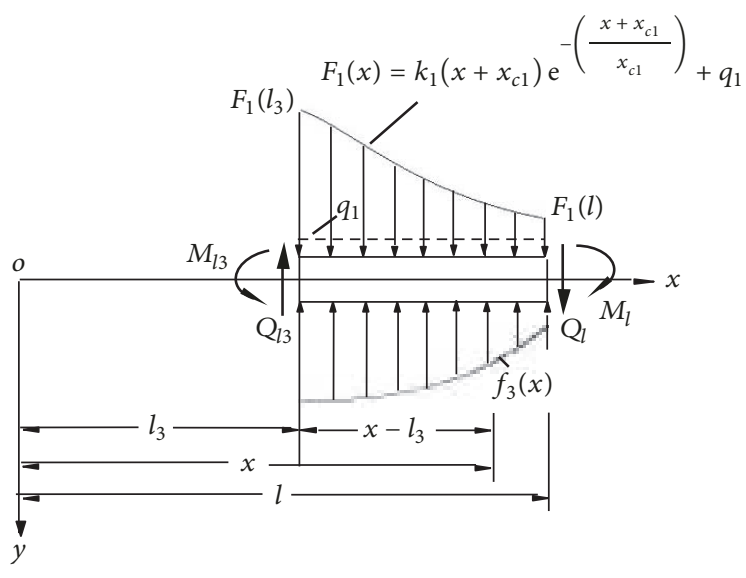

(b)

FIGURE 8: Charts of isolating body of the rock beam before first breaking.

reported in literature [20], the solution form of the differential equation for the deflection of semi-infinite elastic foundation beam in zone $(-\infty, 0]$ is the same as reported in the literature [20], and it is denoted as follows:

$$
\begin{aligned}
& y_{2}(x) \\
& =\mathrm{e}^{\beta x}\left(d_{1} \cos \beta x+d_{2} \sin \beta x\right)+\frac{q_{2}}{4 \beta^{4} E I}+\frac{k_{2}}{E I} \\
& \cdot \frac{x_{\mathrm{c} 2}^{5}}{1+4 \beta^{4} x_{\mathrm{c} 2}^{4}}\left[\frac{x_{\mathrm{c} 2}-x}{x_{\mathrm{c} 2}}+\frac{4}{1+4 \beta^{4} x_{\mathrm{c} 2}^{4}}\right] \mathrm{e}^{\left(x-x_{\mathrm{c} 2}\right) / x_{\mathrm{c} 2},} \\
& \quad(x \leq 0)
\end{aligned}
$$

whereas that in zone $\left[0, l_{4}\right]$ is also the same as that reported in the literature [20] and can be expressed as follows:

$$
\begin{aligned}
y_{21}(x)=d_{3} \sin \beta x \sinh \beta x+d_{4} \sin \beta x \cosh \beta x+d_{5} \\
\cdot \cos \beta x \sinh \beta x+d_{6} \cos \beta x \cosh \beta x \\
+\frac{q_{1}}{4 \beta^{4} E I}+d_{5} \cos \beta x \sinh \beta x+d_{6} \cos \beta x \\
\cdot \cosh \beta x+\frac{q_{1}}{4 \beta^{4} E I}+\frac{k_{1}}{E I} \\
\cdot \frac{x_{\mathrm{c} 1}^{5}}{1+4 \beta^{4} x_{\mathrm{c} 1}^{4}}\left[\frac{x+x_{\mathrm{c} 1}}{x_{\mathrm{c} 1}}+\frac{4}{1+4 \beta^{4} x_{\mathrm{c} 1}^{4}}\right] \\
\cdot \mathrm{e}^{-\left(x+x_{\mathrm{c} 1}\right) / x_{\mathrm{c} 1}}, \quad\left(0 \leq x \leq l_{4}\right)
\end{aligned}
$$

The values of integral constants $d_{1}-d_{6}$ in (14) and (15) are different from the values of $d_{1}-d_{6}$ reported in the literature [20]; therefore, these values should be redetermined according to the parameters of the hardened zone of coal seam.

3.2. Deflection Equation of Rock Beam above the Hardened Zone of Coal Seam. The distributed load $F_{1}(x)$ was applied above the rock beam in zone $\left[l_{4}, l_{3}\right]$ shown in Figure 4 , and the support pressure of hardened zone of coal seam $F_{4}(x)$ was applied below the rock beam. The deflection of the rock beam in zone $\left[l_{4}, l_{3}\right]$ was denoted as $y_{22}(x)$, and similar to (13), the differential equations for the deflection of the rock beam above the hardened zone of coal seam $\left[l_{4}, l_{3}\right]$ can be written as follows:

$$
\begin{aligned}
y_{22}{ }^{(4)}(x)= & \frac{q_{1}}{E I}+\frac{k_{1}}{E I}\left(x+x_{\mathrm{c} 1}\right) \mathrm{e}^{-\left(x+x_{\mathrm{c} 1}\right) / x_{\mathrm{cl}}}-\frac{q_{2}}{E I} \\
& -\frac{k_{4}}{E I}\left[\left(l_{3}+x_{\mathrm{c} 4}\right)-x\right] \mathrm{e}^{\left(x-l_{3}-x_{\mathrm{c} 4}\right) / x_{\mathrm{c} 4}}, \\
& \left(l_{4} \leq x \leq l_{3}\right)
\end{aligned}
$$

Figure 8(a) shows the chart of the isolating body of the rock beam above the hardened zone of coal seam in Figure 4 . By calculating the moments of the forces from the left of $x$ cross-section with respect to $x$ cross-section in Figure 8(a), the equation of the bending moment of the rock beam in zone $\left[l_{4}, l_{3}\right]$ can be obtained as follows:

$$
\begin{aligned}
& M_{22}(x)=M_{l 4}-Q_{l 4}\left(x-l_{4}\right)+\frac{q_{1}-q_{2}}{2}\left(x-l_{4}\right)^{2} \\
& +k_{1} x_{\mathrm{c} 1}^{3} \times\left\{\left[\frac{x+x_{\mathrm{c} 1}}{x_{\mathrm{c} 1}}+2\right] \mathrm{e}^{-\left(x+x_{\mathrm{c} 1}\right) / x_{\mathrm{c} 1}}\right. \\
& -\left[\left(\frac{l_{4}+x_{\mathrm{c} 1}}{x_{\mathrm{c} 1}}\right)^{2}+2\left(\frac{l_{4}+x_{\mathrm{c} 1}}{x_{\mathrm{c} 1}}\right)+2\right. \\
& \left.\left.-\left(\frac{l_{4}+x_{\mathrm{c} 1}}{x_{\mathrm{c} 1}}+1\right)\left(\frac{x+x_{\mathrm{c} 1}}{x_{\mathrm{c} 1}}\right)\right] \mathrm{e}^{-\left(l_{4}+x_{\mathrm{c} 1}\right) / x_{\mathrm{c} 1}}\right\} \\
& -k_{4} x_{\mathrm{c} 4}^{3} \times\left\{\left[2-\frac{x-l_{3}-x_{\mathrm{c} 4}}{x_{\mathrm{c} 4}}\right] \mathrm{e}^{\left(x-l_{3}-x_{\mathrm{c} 4}\right) / x_{\mathrm{c} 4}}\right. \\
& -\left[\left(\frac{l_{4}-l_{3}-x_{\mathrm{c} 4}}{x_{\mathrm{c} 4}}\right)^{2}-2\left(\frac{l_{4}-l_{3}-x_{\mathrm{c} 4}}{x_{\mathrm{c} 4}}\right)+2\right.
\end{aligned}
$$




$$
\begin{aligned}
& \left.-\left(\frac{l_{4}-l_{3}-x_{\mathrm{c} 4}}{x_{\mathrm{c} 4}}-1\right)\left(\frac{x-l_{3}-x_{\mathrm{c} 4}}{x_{\mathrm{c} 4}}\right)\right] \\
& \left.\times \mathrm{e}^{\left(l_{4}-l_{3}-x_{\mathrm{c} 4}\right) / x_{\mathrm{c} 4}}\right\}, \quad\left(l_{4} \leq x \leq l_{3}\right)
\end{aligned}
$$

The sum of vertical forces on the isolating body in Figure 8(a) was calculated, and the shearing force of the leftend cross-section of the rock beam in zone $\left[l_{4}, l_{3}\right]$ can be obtained from $\sum F_{y}=0$ :

$$
\begin{aligned}
Q_{l 4} & =Q_{l 3}+\left(q_{1}-q_{2}\right)\left(l_{3}-l_{4}\right) \\
& +k_{1} x_{\mathrm{c} 1}^{2}\left[\left(\frac{l_{4}+x_{\mathrm{c} 1}}{x_{\mathrm{c} 1}}+1\right) \mathrm{e}^{-\left(l_{4}+x_{\mathrm{c} 1}\right) / x_{\mathrm{c} 1}}\right. \\
& \left.-\left(\frac{l_{3}+x_{\mathrm{c} 1}}{x_{\mathrm{c} 1}}+1\right) \mathrm{e}^{-\left(l_{3}+x_{\mathrm{c} 1}\right) / x_{\mathrm{c} 1}}\right]-k_{4} x_{\mathrm{c} 4}^{2}\left[2 \mathrm{e}^{-1}\right. \\
& \left.+\left(\frac{l_{4}-l_{3}-x_{\mathrm{c} 4}}{x_{\mathrm{c} 4}}-1\right) \mathrm{e}^{\left(l_{4}-l_{3}-x_{\mathrm{c} 4}\right) / x_{\mathrm{c} 4}}\right]
\end{aligned}
$$

By calculating the moments of the forces of the isolating body in Figure 8(a) with respect to the left-end $x=l_{4}$ crosssection of the rock beam, i.e., the bending moment of the left-end cross-section of the rock beam in this zone, can be obtained from $\sum M_{l 4}=0$ :

$$
\begin{aligned}
M_{l 4} & =M_{l 3}+Q_{l 3}\left(l_{3}-l_{4}\right)+\frac{\left(q_{1}-q_{2}\right)}{2}\left(l_{3}-l_{4}\right)^{2} \\
& +k_{1} x_{\mathrm{c} 1}^{3}\left\{\left[\frac{l_{4}+x_{\mathrm{c} 1}}{x_{\mathrm{c} 1}}+2\right] \times \mathrm{e}^{-\left(l_{4}+x_{\mathrm{c} 1}\right) / x_{\mathrm{c} 1}}\right. \\
& -\left[\left(\frac{l_{3}+x_{\mathrm{c} 1}}{x_{\mathrm{c} 1}}\right)^{2}+2\left(\frac{l_{3}+x_{\mathrm{c} 1}}{x_{\mathrm{c} 1}}\right)+2\right. \\
& \left.\left.-\left(\frac{l_{3}+x_{\mathrm{c} 1}}{x_{\mathrm{c} 1}}+1\right) \times\left(\frac{l_{4}+x_{\mathrm{c} 1}}{x_{\mathrm{c} 1}}\right)\right] \mathrm{e}^{-\left(l_{3}+x_{\mathrm{c} 1}\right) / x_{\mathrm{c} 1}}\right\} \\
& +k_{4} x_{\mathrm{c} 4}^{3}\left\{\mathrm{e}^{-1}\left(5+2 \frac{l_{4}-l_{3}-x_{\mathrm{c} 4}}{x_{\mathrm{c} 4}}\right)-(2\right. \\
& \left.\left.-\frac{l_{4}-l_{3}-x_{\mathrm{c} 4}}{x_{\mathrm{c} 4}}\right) \mathrm{e}^{\left(l_{4}-l_{3}-x_{\mathrm{c} 4}\right) / x_{\mathrm{c} 4}}\right\}
\end{aligned}
$$

In (18) and (19), $Q_{l 3}$ and $M_{l 3}$ are the shear forces and bending moments of the left end of the isolating body shown in Figure $8(\mathrm{a})$ or the right end of the isolating body shown in Figure 8(b).

By computing twice the integral of (17), the equation of the deflection of the rock beam above the hardened zone of coal seam $\left[l_{4}, l_{3}\right]$ can be expressed as follows:

$$
\begin{aligned}
& E I y_{22}(x)=\frac{M_{l 4}}{2}\left(x-l_{4}\right)^{2}-\frac{Q_{l 4}}{6}\left(x-l_{4}\right)^{3} \\
& +\frac{q_{1}-q_{2}}{24}\left(x-l_{4}\right)^{4}+k_{1} x_{\mathrm{c} 1}^{5}\left\{\left[\frac{x+x_{\mathrm{c} 1}}{x_{\mathrm{c} 1}}+4\right]\right. \\
& \cdot \mathrm{e}^{-\left(x+x_{\mathrm{c} 1}\right) / x_{\mathrm{c} 1}}
\end{aligned}
$$

$$
\begin{aligned}
& -\left\{\left[\left(\frac{l_{4}+x_{\mathrm{c} 1}}{x_{\mathrm{c} 1}}\right)^{2}+2\left(\frac{l_{4}+x_{\mathrm{c} 1}}{x_{\mathrm{c} 1}}\right)+2\right]\right. \\
& \times \frac{1}{2}\left(\frac{x+x_{\mathrm{c} 1}}{x_{\mathrm{c} 1}}\right)^{2} \\
& \left.\left.-\frac{1}{6}\left(\frac{l_{4}+x_{\mathrm{c} 1}}{x_{\mathrm{c} 1}}+1\right)\left(\frac{x+x_{\mathrm{c} 1}}{x_{\mathrm{c} 1}}\right)^{3}\right\} \mathrm{e}^{-\left(l_{4}+x_{\mathrm{c} 1}\right) / x_{\mathrm{c} 1}}\right\} \\
& -k_{4} x_{\mathrm{c} 4}^{5}\left\{\left(4-\frac{x-l_{3}-x_{\mathrm{c} 4}}{x_{\mathrm{c} 4}}\right) \mathrm{e}^{\left(x-l_{3}-x_{\mathrm{c} 4}\right) / x_{\mathrm{c} 4}}\right. \\
& -\left\{\frac{1}{2}\left[\left(\frac{l_{4}-l_{3}-x_{\mathrm{c} 4}}{x_{\mathrm{c} 4}}\right)^{2}-2\left(\frac{l_{4}-l_{3}-x_{\mathrm{c} 4}}{x_{\mathrm{c} 4}}\right)+2\right]\right. \\
& \left.\left.\times\left(\frac{x-l_{3}-x_{\mathrm{c} 4}}{x_{\mathrm{c} 4}}\right)^{2}\right]+l_{1} \leq x \leq l_{3}\right) \\
& \left.-\frac{1}{6}\left(\frac{l_{4}-l_{3}-x_{\mathrm{c} 4}}{x_{\mathrm{c} 4}-1}\right)\left(\frac{x-l_{3}-x_{\mathrm{c} 4}}{x_{\mathrm{c} 4}}\right)^{3}\right\}
\end{aligned}
$$

where $j_{1}$ and $j_{2}$ are integral constants determined from the continuity conditions.

3.3. Deflection Equation of Rock Beam above the Softened Zone of Coal Seam. Figure 8(b) shows the chart of the isolating body of the rock beam above the softened zone of coal seam shown in Figure 4 . The distributed load $F_{1}(x)$ was applied above the rock beam in zone $\left[l_{3}, l\right]$, and the support pressure $f_{3}(x)$ of the softened zone of coal seam was applied beneath that. The deflection of rock beam in the softened zone of coal seam $\left[l_{3}, l\right]$ was denoted as $y_{23}(x)$, and the form of $y_{23}(x)$ is the same as that reported in the literature [20]:

$$
\begin{aligned}
E I & y_{23}(x)=\frac{M_{l 3}}{2}\left(x-l_{3}\right)^{2}-\frac{Q_{l 3}}{6}\left(x-l_{3}\right)^{3}+\frac{q_{1}}{24}(x \\
& \left.-l_{3}\right)^{4}+k_{1} x_{\mathrm{c} 1}^{5}\left\{\left[\frac{x+x_{\mathrm{c} 1}}{x_{\mathrm{c} 1}}+4\right] \mathrm{e}^{-\left(x+x_{\mathrm{c} 1}\right) / x_{\mathrm{c} 1}}\right. \\
& -\left\{\left[\left(\frac{l_{3}+x_{\mathrm{c} 1}}{x_{\mathrm{c} 1}}\right)^{2}+2\left(\frac{l_{3}+x_{\mathrm{c} 1}}{x_{\mathrm{c} 1}}\right)+2\right]\right. \\
& \left.\times \frac{1}{2}\left(\frac{x+x_{\mathrm{c} 1}}{x_{\mathrm{c} 1}}\right)^{2}-\frac{1}{6}\left(\frac{l_{3}+x_{\mathrm{c} 1}}{x_{\mathrm{c} 1}}+1\right)\left(\frac{x+x_{\mathrm{c} 1}}{x_{\mathrm{c} 1}}\right)^{3}\right\} \\
& \left.\cdot \mathrm{e}^{-\left(l_{3}+x_{\mathrm{c} 1}\right) / x_{\mathrm{c} 1}}\right\}-k_{3} x_{\mathrm{c} 3}^{5}\left[\left(\frac{l_{3}+x_{\mathrm{c} 3}-x}{x_{\mathrm{c} 3}}+4\right)\right. \\
& \cdot \mathrm{e}^{\left(x-l_{3}-x_{\mathrm{c} 3}\right) / x_{\mathrm{c} 3}}+\frac{\mathrm{e}^{-1}}{3}\left(\frac{l_{3}+x_{\mathrm{c} 3}-x}{x_{\mathrm{c} 3}}\right)^{3}-\frac{5}{2} \\
& \left.\cdot \mathrm{e}^{-1}\left(\frac{l_{3}+x_{\mathrm{c} 3}-x}{x_{\mathrm{c} 3}}\right)^{2}\right]+g_{1}\left(x-l_{3}\right)+g_{2},
\end{aligned}
$$

$\left(l_{3} \leq x \leq l\right)$ 
In (21), $Q_{l 3}$ and $M_{l 3}$ are the shear forces and bending moments of the left-end cross-section of the isolating body shown in Figure 8(b). The sum of the vertical forces shown in Figure 8(b) was computed, and the shearing force of the left-end cross-section of the rock beam in zone $\left[l_{3}, l\right]$ can be obtained from $\sum F_{y}=0$ :

$$
\begin{aligned}
Q_{l 3} & =Q_{l}+q_{1}\left(l-l_{3}\right) \\
& +k_{1} x_{\mathrm{c} 1}^{2}\left[\left(\frac{l_{3}+x_{\mathrm{c} 1}}{x_{\mathrm{c} 1}}+1\right) \mathrm{e}^{-\left(l_{3}+x_{\mathrm{c} 1}\right) / x_{\mathrm{c} 1}}\right. \\
& \left.-\left(\frac{l+x_{\mathrm{c} 1}}{x_{\mathrm{c} 1}}+1\right) \mathrm{e}^{-\left(l+x_{\mathrm{c} 1}\right) / x_{\mathrm{c} 1}}\right] \\
& -k_{3} x_{\mathrm{c} 3}^{2}\left[\left(\frac{l_{3}+x_{\mathrm{c} 3}-l}{x_{\mathrm{c} 3}}+1\right) \mathrm{e}^{\left(l-l_{3}-x_{\mathrm{c} 3}\right) / x_{c 3}}-2 \mathrm{e}^{-1}\right]
\end{aligned}
$$

By calculating the moments of the forces with respect to the left-end $x=l_{3}$ cross-section shown in Figure 8(b), the equation for the bending moments of the rock beam in this zone can be obtained from $\sum M_{l 3}=0$ :

$$
M_{l 3}=M_{l}+Q_{l}\left(l-l_{3}\right)+\frac{q_{1}}{2}\left(l-l_{3}\right)^{2}
$$

$$
\begin{aligned}
& +k_{1} x_{\mathrm{c} 1}^{3}\left\{\left[\frac{l_{3}+x_{\mathrm{c} 1}}{x_{\mathrm{c} 1}}+2\right] \times \mathrm{e}^{-\left(l_{3}+x_{\mathrm{c} 1}\right) / x_{\mathrm{c} 1}}\right. \\
& -\left\{\left[\left(\frac{l+x_{\mathrm{c} 1}}{x_{\mathrm{c} 1}}\right)^{2}+2\left(\frac{l+x_{\mathrm{c} 1}}{x_{\mathrm{c} 1}}\right)+2\right]\right. \\
& \left.\left.-\left(\frac{l+x_{\mathrm{c} 1}}{x_{\mathrm{c} 1}}+1\right) \times\left(\frac{l_{3}+x_{\mathrm{c} 1}}{x_{\mathrm{c} 1}}\right)\right\} \mathrm{e}^{-\left(l+x_{\mathrm{c} 1}\right) / x_{\mathrm{c} 1}}\right\} \\
& -k_{3} x_{\mathrm{c} 3}^{3}\left\{3 \mathrm{e}^{-1}-\left[\left(\frac{l-l_{3}-x_{\mathrm{c} 3}}{x_{\mathrm{c} 3}}\right)^{2}\right.\right. \\
& \left.\left.-\left(\frac{l-l_{3}-x_{\mathrm{c} 3}}{x_{\mathrm{c} 3}}\right)+1\right] \mathrm{e}^{\left(l-l_{3}-x_{\mathrm{c} 3}\right) / x_{\mathrm{c} 3}}\right\}
\end{aligned}
$$

In (22) and (23), $Q_{l}$ and $M_{l}$ are the shear forces and bending moments for the left end of the isolating body of rock beam shown in Figure 8(b) and $x=l$ cross-section of the rock beam in the goaf shown in Figure 4.

3.4. Deflection Equation of Rock Beam in Goaf. The deflection equations of the rock beam in zones $\left[l, l+L_{k}\right]$ and $\left[l+L_{k}, l+L\right]$ are shown in Figure 4. $y_{11}(x), y_{12}(x), y_{11}(x)$, and $y_{12}(x)$ are the same as those reported in the literature [20]:

$$
\begin{aligned}
& E I y_{11}(x)=\frac{M_{l}}{2}(x-l)^{2}-\frac{Q_{l}}{6}(x-l)^{3}+\frac{q_{1}}{24}(x-l)^{4}+k_{1} x_{\mathrm{c} 1}^{5} \\
& \quad \times\left\{\left[\frac{x+x_{\mathrm{c} 1}}{x_{\mathrm{c} 1}}+4\right] \mathrm{e}^{-\left(x+x_{\mathrm{c} 1}\right) / x_{\mathrm{cl}}}-\left\{\left[\left(\frac{l+x_{\mathrm{c} 1}}{x_{\mathrm{c} 1}}\right)^{2}+2\left(\frac{l+x_{\mathrm{c} 1}}{x_{\mathrm{c} 1}}\right)+2\right] \times \frac{1}{2}\left(\frac{x+x_{\mathrm{c} 1}}{x_{\mathrm{c} 1}}\right)^{2}-\frac{1}{6}\left(\frac{l+x_{\mathrm{c} 1}}{x_{\mathrm{cl}}}+1\right)\left(\frac{x+x_{\mathrm{c} 1}}{x_{\mathrm{c} 1}}\right)^{3}\right\} \mathrm{e}^{-\left(l+x_{\mathrm{c} 1}\right) / x_{\mathrm{c} 1}}\right\} \\
& \quad-\frac{p_{\mathrm{o}}(x-l)^{4}}{24}-\frac{\left(p_{k}-p_{\mathrm{o}}\right)}{120 L_{k}}(x-l)^{5}+c_{1} x+c_{2}, \quad\left(l \leq x \leq l+L_{\mathrm{k}}\right) \\
& E \\
& \quad E y_{12}(x)=\frac{M_{l}}{2}(x-l)^{2}-\frac{\mathrm{Q}_{l}}{6}(x-l)^{3}+\frac{q_{1}}{24}(x-l)^{4}+k_{1} x_{\mathrm{c} 1}^{5} \\
& \quad \times\left\{\left[\frac{x+x_{\mathrm{c} 1}}{x_{\mathrm{c} 1}}+4\right] \mathrm{e}^{-\left(x+x_{\mathrm{c} 1}\right) / x_{\mathrm{cl}}-}-\left\{\left[\left(\frac{l+x_{\mathrm{c} 1}}{x_{\mathrm{c} 1}}\right)^{2}+2\left(\frac{l+x_{\mathrm{c} 1}}{x_{\mathrm{c} 1}}\right)+2\right] \times \frac{1}{2}\left(\frac{x+x_{\mathrm{c} 1}}{x_{\mathrm{c} 1}}\right)^{2}-\frac{1}{6}\left(\frac{l+x_{\mathrm{c} 1}}{x_{\mathrm{c} 1}}+1\right)\left(\frac{x+x_{\mathrm{c} 1}}{x_{\mathrm{c} 1}}\right)^{3}\right\} \mathrm{e}^{-\left(l+x_{\mathrm{c} 1}\right) / x_{\mathrm{c} 1}}\right\} \\
& \quad-p_{\mathrm{o}} L_{\mathrm{k}}\left[\frac{(x-l)^{3}}{6}-\frac{L_{\mathrm{k}}}{4}(x-l)^{2}\right]-\frac{\left(p_{\mathrm{k}}-p_{\mathrm{o}}\right) L_{\mathrm{k}}}{2}\left[\frac{(x-l)^{3}}{6}-\frac{L_{\mathrm{k}}(x-l)^{2}}{3}\right]+c_{3} x+c_{4}, \quad\left(l+L_{k} \leq x \leq l+L\right)
\end{aligned}
$$

3.5. Boundary and Continuity Conditions for Deflection of Rock Beam in All Zones. The boundary and continuity conditions for the rock beam model shown in Figure 4 are listed as follows:

$$
\begin{aligned}
y_{2}(-\infty) & =\frac{q_{2}}{C}, \\
y_{2}^{\prime}(-\infty) & =0 \\
y_{2}(0) & =y_{21}(0), \\
y_{2}^{\prime}(0) & =y_{21}^{\prime}(0), \\
y_{2}^{\prime \prime}(0) & =y_{21}^{\prime \prime}(0),
\end{aligned}
$$

$$
\begin{gathered}
y_{2}^{\prime \prime \prime}(0)=y_{21}^{\prime \prime \prime}(0) \\
y_{21}\left(l_{4}\right)=y_{22}\left(l_{4}\right), \\
y_{21}^{\prime}\left(l_{4}\right)=y_{22}^{\prime}\left(l_{4}\right), \\
y_{21}^{\prime \prime}\left(l_{4}\right)=\frac{M_{l 4}}{E I}, \\
y_{21}^{\prime \prime \prime}\left(l_{4}\right)=-\frac{Q_{l 4}}{E I}, \\
E I y_{21}^{(4)}\left(l_{4}\right)=E I y_{22}^{(4)}\left(l_{4}\right)
\end{gathered}
$$




$$
\begin{aligned}
y_{22}\left(l_{3}\right) & =y_{23}\left(l_{3}\right), \\
y_{22}^{\prime}\left(l_{3}\right) & =y_{23}^{\prime}\left(l_{3}\right), \\
y_{22}^{\prime \prime}\left(l_{3}\right) & =\frac{M_{l 3}}{E I}, \\
y_{22}^{\prime \prime \prime}\left(l_{3}\right) & =-\frac{Q_{l 3}}{E I} \\
y_{23}(l) & =y_{11}(l), \\
y_{23}^{\prime}(l) & =y_{11}^{\prime}(l), \\
y_{23}^{\prime \prime}(l) & =\frac{M_{l}}{E I}, \\
y_{23}^{\prime \prime \prime}(l) & =-\frac{Q_{l}}{E I} \\
y_{11}\left(l+L_{k}\right) & =y_{12}\left(l+L_{k}\right), \\
y_{11}^{\prime}\left(l+L_{k}\right) & =y_{12}^{\prime}\left(l+L_{k}\right) \\
Q_{12}(l+L) & =0, \\
y_{12}^{\prime}(l+L) & =0
\end{aligned}
$$

The minus symbols ahead of $Q_{l 4}, Q_{l 3}$, and $Q_{l}$ in (26c), (26d), and (26e) are because of the following: the bending moment of fiber tension in the upper side of rock beam is positive, and the corresponding shear force is positive if anticlockwise. The shear forces $Q_{14}, Q_{13}$, and $Q_{l}$ shown in Figures $8(\mathrm{a})$ and $8(\mathrm{~b})$ are clockwise; therefore, they are labeled with minus signs.

By satisfying (26a), (26b), (26c), (26d), (26e), (26f), and $(26 \mathrm{~g})$ for boundary and continuity conditions, 14 integral constants in (14), (15), (20), (21), (24), and (25) can be determined. Owing to the introduction of the hardened zone of coal seam, one more equation was added to the deflection equations of rock beam compared with literature [20], i.e., in (20), two more integral constants, $j_{1}$ and $j_{2}$, were added, and the continuity condition (26c) was added in (26a), (26b), (26c), (26d), (26e), (26f), and (26g). Therefore, the integral constants $d_{1}-d_{6}, g_{1}, g_{2}$, and $c_{1}-c_{4}$ in (14), (15), (21), (24), and (25) are totally different from those in the corresponding equations reported in the literature [20].

The relationship between the equations of bending moment and deflection of rock beam in each zone can be expressed as follows:

$$
M(x)=E I y^{\prime \prime}(x)
$$

The relationship between the equations of shear force and bending moment and deflection can be expressed as follows:

$$
Q(x)=\frac{\mathrm{d} M(x)}{\mathrm{d} x}=E I y^{\prime \prime \prime}(x)
$$

\section{Determination of Integral Constants in Deflection Equations}

4.1. Relationship among Integral Constants $c_{1}-c_{4}, M_{l}, g_{1}$, and $g_{2}$. Because the rock beam model shown in Figure 4 is statically indeterminate, a supplementary equation should be established through the geometric condition of $y_{11}^{\prime}(l+L)=0$ in (26g), defined as follows:

$$
\mathcal{C}_{3}=\frac{Q_{l} L^{2}}{2}-M_{l} L-D_{1}
$$

to determine the relationship between $c_{3}$ of $y_{12}(x)$ in (25) and right-end bending moment $M_{l}$ shown in Figure 8(b), where $M_{l}$ is an unknown variable to be determined. In (29),

$$
\begin{aligned}
D_{1} & =\frac{q_{1} L^{3}}{6}+k_{1} x_{\mathrm{c} 1}^{4}\left\{\left\{\frac{1}{2}\left(\frac{l+x_{\mathrm{c} 1}}{x_{\mathrm{c} 1}}+1\right)\right.\right. \\
\cdot & \left(\frac{L+l+x_{\mathrm{c} 1}}{x_{\mathrm{c} 1}}\right)^{2}-\left(\frac{L+l+x_{\mathrm{c} 1}}{x_{\mathrm{c} 1}}\right) \\
& \left.\cdot\left[\left(\frac{l+x_{\mathrm{c} 1}}{x_{\mathrm{c} 1}}\right)^{2}+2\left(\frac{l+x_{\mathrm{c} 1}}{x_{\mathrm{c} 1}}\right)+2\right]\right\} \mathrm{e}^{-\left(l+x_{\mathrm{c} 1}\right) / x_{\mathrm{c} 1}} \\
& \left.-\left(\frac{L+l+x_{\mathrm{c} 1}}{x_{\mathrm{c} 1}}+3\right) \mathrm{e}^{-\left(L+l+x_{\mathrm{c} 1}\right) / x_{\mathrm{c} 1}}\right\}-p_{\mathrm{o}} L_{\mathrm{k}}\left[\frac{L^{2}}{2}\right. \\
& \left.-\frac{L_{\mathrm{k}} L}{2}\right]-\frac{\left(p_{\mathrm{k}}-p_{\mathrm{o}}\right) L_{\mathrm{k}}}{2}\left[\frac{L^{2}}{2}-\frac{2 L_{\mathrm{k}} L}{3}\right]
\end{aligned}
$$

According to the condition $Q_{12}(l+L) /(E I)=0$ in $(26 \mathrm{~g})$ and $\sum F_{y}=0$, the right-hand term, i.e., the shear force in (29), can be obtained as follows:

$$
\begin{aligned}
\mathrm{Q}_{l} & =q_{1} L+k_{1} x_{\mathrm{c} 1}^{2}\left[\left(\frac{l+x_{\mathrm{c} 1}}{x_{\mathrm{c} 1}}+1\right) \mathrm{e}^{-\left(l+x_{\mathrm{c} 1}\right) / x_{\mathrm{c} 1}}\right. \\
& \left.-\left(\frac{L+l+x_{\mathrm{c} 1}}{x_{\mathrm{c} 1}}+1\right) \times \mathrm{e}^{-\left(L+l+x_{\mathrm{c} 1}\right) / x_{\mathrm{c} 1}}\right]-p_{\mathrm{o}} L_{k} \\
& -\frac{\left(p_{k}-p_{\mathrm{o}}\right) L_{k}}{2}
\end{aligned}
$$

Using the first derivative of (24) and (25) and the condition $y_{11}^{\prime}\left(l+L_{k}\right)=y_{12}^{\prime}\left(l+L_{k}\right)$ in (26f), the following expression can be obtained:

$$
c_{1}=c_{3}+\frac{p_{\mathrm{o}} L_{k}^{3}}{6}+\frac{\left(p_{\mathrm{k}}-p_{\mathrm{o}}\right) L_{k}^{3}}{8}
$$

Regarding (24) and (25), according to the condition $y_{11}(l$ $\left.+L_{k}\right)=y_{12}\left(l+L_{k}\right)$ in $(26 \mathrm{f})$, the following expression can be obtained:

$$
c_{4}=\left(c_{1}-c_{3}\right)\left(l+L_{k}\right)+c_{2}-\frac{p_{\mathrm{o}} L_{k}^{4}}{8}-\frac{11\left(p_{\mathrm{k}}-p_{\mathrm{o}}\right) L_{k}^{4}}{120}
$$


By substituting (21) and (24) into the conditions $y_{23}(l)=$ $y_{11}(l)$ and $y_{23}^{\prime}(l)=y_{11}^{\prime}(l)$ in $(26 \mathrm{e})$, the followings equations can be obtained:

$$
\begin{gathered}
\frac{M_{l 3}}{2}\left(l-l_{3}\right)^{2}+D_{2}+g_{1}\left(l-l_{3}\right)+g_{2}=c_{1} l+c_{2}+D_{3} \\
M_{l 3}\left(l-l_{3}\right)+D_{4}+g_{1}=c_{1}+D_{5}
\end{gathered}
$$

where

$$
\begin{aligned}
& D_{2}=-\frac{Q_{l 3}}{6}\left(l-l_{3}\right)^{3}+\frac{q_{1}}{24}\left(l-l_{3}\right)^{4}+k_{1} x_{c 1}^{5} \\
& \times\left\{\frac{1}{6}\left(\frac{l+x_{\mathrm{c} 1}}{x_{\mathrm{c} 1}}\right)^{3}\left(\frac{l_{3}+x_{\mathrm{c} 1}}{x_{\mathrm{c} 1}}+1\right)-\frac{1}{2}\left(\frac{l+x_{\mathrm{c} 1}}{x_{\mathrm{c} 1}}\right)^{2}\right. \\
& \left.\cdot\left[\left(\frac{l_{3}+x_{\mathrm{cl}}}{x_{\mathrm{cl}}}\right)^{2}+2\left(\frac{l_{3}+x_{\mathrm{cl}}}{x_{\mathrm{cl}}}\right)+2\right]\right\} \mathrm{e}^{-\left(l_{3}+x_{\mathrm{cl}}\right) / x_{\mathrm{cl}}} \\
& -k_{3} x_{c 3}^{5}\left[\left(\frac{l_{3}+x_{c 3}-l}{x_{c 3}}+4\right) \mathrm{e}^{\left(l-l_{3}-x_{c 3}\right) / x_{c 3}}\right. \\
& \left.+\frac{\mathrm{e}^{-1}}{3}\left(\frac{l_{3}+x_{\mathrm{c} 3}-l}{x_{\mathrm{c} 3}}\right)^{3}-\frac{5}{2} \mathrm{e}^{-1}\left(\frac{l_{3}+x_{\mathrm{c} 3}-l}{x_{\mathrm{c} 3}}\right)^{2}\right] \\
& D_{3}=-k_{1} x_{\mathrm{c} 1}^{5}\left[\frac{1}{3}\left(\frac{l+x_{\mathrm{c} 1}}{x_{\mathrm{c} 1}}\right)^{4}+\frac{5}{6}\left(\frac{l+x_{\mathrm{c} 1}}{x_{\mathrm{c} 1}}\right)^{3}\right. \\
& \left.+\left(\frac{l+x_{\mathrm{c} 1}}{x_{\mathrm{c} 1}}\right)^{2}\right] \mathrm{e}^{-\left(l+x_{\mathrm{c} 1}\right) / x_{\mathrm{c} 1}} \\
& D_{4}=-\frac{Q_{l 3}}{2}\left(l-l_{3}\right)^{2}+\frac{q_{1}}{6}\left(l-l_{3}\right)^{3}+k_{1} x_{\mathrm{c} 1}^{4} \\
& \times\left\{\frac{1}{2}\left(\frac{l+x_{\mathrm{c} 1}}{x_{\mathrm{c} 1}}\right)^{2}\left(\frac{l_{3}+x_{\mathrm{c} 1}}{x_{\mathrm{c} 1}}+1\right)-\left(\frac{l+x_{\mathrm{c} 1}}{x_{\mathrm{c} 1}}\right)\right. \\
& \left.\cdot\left[\left(\frac{l_{3}+x_{\mathrm{c} 1}}{x_{\mathrm{c} 1}}\right)^{2}+2\left(\frac{l_{3}+x_{\mathrm{c} 1}}{x_{\mathrm{c} 1}}\right)+2\right]\right\} \mathrm{e}^{-\left(l_{3}+x_{\mathrm{c} 1}\right) / x_{\mathrm{c} 1}} \\
& -k_{3} x_{\mathrm{c} 3}^{4}\left[\left(\frac{l_{3}+x_{\mathrm{c} 1}-l}{x_{\mathrm{c} 1}}+3\right) \times \mathrm{e}^{\left(l-l_{3}-x_{\mathrm{c} 3}\right) / x_{\mathrm{c} 3}}\right. \\
& \left.-\mathrm{e}^{-1}\left(\frac{l_{3}+x_{\mathrm{c} 3}-l}{x_{\mathrm{c} 3}}\right)^{2}+5 \mathrm{e}^{-1}\left(\frac{l_{3}+x_{\mathrm{c} 3}-l}{x_{\mathrm{c} 3}}\right)\right] \\
& D_{5}=-k_{1} x_{\mathrm{c} 1}^{4}\left[\frac{1}{2}\left(\frac{l+x_{\mathrm{c} 1}}{x_{\mathrm{c} 1}}\right)^{3}+\frac{3}{2}\left(\frac{l+x_{\mathrm{c} 1}}{x_{\mathrm{c} 1}}\right)^{2}\right. \\
& \left.+2\left(\frac{l+x_{\mathrm{c} 1}}{x_{\mathrm{c} 1}}\right)\right] \mathrm{e}^{-\left(l+x_{\mathrm{c} 1}\right) / x_{\mathrm{c} 1}}
\end{aligned}
$$

Equation (23) can be written in the following form:

$$
M_{l 3}=M_{l}+D_{6}
$$

where

$$
\begin{aligned}
D_{6} & =Q_{l}\left(l-l_{3}\right)+\frac{q_{1}}{2}\left(l-l_{3}\right)^{2}+k_{1} x_{\mathrm{c} 1}^{3}\left\{\left[\frac{l_{3}+x_{\mathrm{c} 1}}{x_{\mathrm{c} 1}}\right.\right. \\
& +2] \mathrm{e}^{-\left(l_{3}+x_{\mathrm{c} 1}\right) / x_{\mathrm{c} 1}} \\
& -\left\{\left[\left(\frac{l+x_{\mathrm{c} 1}}{x_{\mathrm{c} 1}}\right)^{2}+2\left(\frac{l+x_{\mathrm{c} 1}}{x_{\mathrm{c} 1}}\right)+2\right]\right. \\
& \left.\left.-\left(\frac{l+x_{\mathrm{c} 1}}{x_{\mathrm{c} 1}}+1\right) \times\left(\frac{l_{3}+x_{\mathrm{c} 1}}{x_{\mathrm{c} 1}}\right)\right\} \mathrm{e}^{-\left(l+x_{\mathrm{c} 1}\right) / x_{\mathrm{c} 1}}\right\} \\
& -k_{3} x_{\mathrm{c} 3}^{3}\left\{3 \mathrm{e}^{-1}-\left[\left(\frac{l-l_{3}-x_{\mathrm{c} 3}}{x_{\mathrm{c} 3}}\right)^{2}\right.\right. \\
& \left.\left.-\left(\frac{l-l_{3}-x_{\mathrm{c} 3}}{x_{\mathrm{c} 3}}\right)+1\right] \mathrm{e}^{\left(l-l_{3}-x_{\mathrm{c} 3}\right) / x_{\mathrm{c} 3}}\right\}
\end{aligned}
$$

The following expression can be obtained from (35) using (29) and (32).

$$
g_{1}=-M_{l}\left(l-l_{3}+L\right)+D_{7}
$$

where

$$
\begin{aligned}
D_{7}= & {\left[\frac{Q_{l} L^{2}}{2}-D_{1}+\frac{p_{\mathrm{o}} L_{k}^{3}}{6}+\frac{\left(p_{\mathrm{k}}-p_{\mathrm{o}}\right) L_{k}^{3}}{8}\right]-D_{4} } \\
& +D_{5}-D_{6}\left(l-l_{3}\right)
\end{aligned}
$$

By substituting (20) and (21) into the conditions $y_{22}\left(l_{3}\right)=$ $y_{23}\left(l_{3}\right), y_{22}^{\prime}\left(l_{3}\right)=y_{23}^{\prime}\left(l_{3}\right)$ in $(26 \mathrm{~d})$, the following equations can be obtained:

$$
\begin{array}{r}
\frac{M_{l 4}}{2}\left(l_{3}-l_{4}\right)^{2}+D_{8}+j_{1}\left(l_{3}-l_{4}\right)+j_{2}=g_{2}+D_{9} \\
M_{l 4}\left(l_{3}-l_{4}\right)+D_{10}+j_{1}=g_{1}+D_{11}
\end{array}
$$

where

$$
\begin{aligned}
D_{8} & =-\frac{Q_{l 4}}{6}\left(l_{3}-l_{4}\right)^{3}+\frac{q_{1}-q_{2}}{24}\left(l_{3}-l_{4}\right)^{4}-k_{1} x_{\mathrm{c} 1}^{5} \\
& \times\left\{\frac{1}{2}\left[\left(\frac{l_{4}+x_{\mathrm{c} 1}}{x_{\mathrm{c} 1}}\right)^{2}+2\left(\frac{l_{4}+x_{\mathrm{c} 1}}{x_{\mathrm{c} 1}}\right)+2\right]\right. \\
& \left.\cdot\left(\frac{l_{3}+x_{\mathrm{c} 1}}{x_{\mathrm{c} 1}}\right)^{2}-\frac{1}{6}\left(\frac{l_{4}+x_{\mathrm{c} 1}}{x_{\mathrm{c} 1}}+1\right)\left(\frac{l_{3}+x_{\mathrm{c} 1}}{x_{\mathrm{c} 1}}\right)^{3}\right\} \\
& \cdot \mathrm{e}^{-\left(l_{4}+x_{\mathrm{c} 1}\right) / x_{\mathrm{c} 1}}-k_{4} x_{\mathrm{c} 4}^{5} \times\left\{5 \mathrm{e}^{-1}\right. \\
& -\frac{1}{2}\left[\left(\frac{l_{4}-l_{3}-x_{\mathrm{c} 4}}{x_{\mathrm{c} 4}}\right)^{2}-\frac{5}{3}\left(\frac{l_{4}-l_{3}-x_{\mathrm{c} 4}}{x_{\mathrm{c} 4}}\right)+\frac{5}{3}\right] \\
& \left.\times \mathrm{e}^{\left(l_{4}-l_{3}-x_{\mathrm{c} 4}\right) / x_{\mathrm{c} 4}}\right\}
\end{aligned}
$$




$$
\begin{aligned}
D_{9} & =-k_{1} x_{\mathrm{c} 1}^{5}\left[\frac{1}{3}\left(\frac{l_{3}+x_{\mathrm{c} 1}}{x_{\mathrm{c} 1}}\right)^{4}+\frac{5}{6}\left(\frac{l_{3}+x_{\mathrm{c} 1}}{x_{\mathrm{c} 1}}\right)^{3}\right. \\
& \left.+\left(\frac{l_{3}+x_{\mathrm{c} 1}}{x_{\mathrm{c} 1}}\right)^{2}\right] \times \mathrm{e}^{-\left(l_{3}+x_{\mathrm{c} 1}\right) / x_{\mathrm{c} 1}}-\frac{17}{6} k_{3} x_{\mathrm{c} 3}^{5} \mathrm{e}^{-1} \\
D_{10} & =-\frac{Q_{l 4}}{2}\left(l_{3}-l_{4}\right)^{2}+\frac{q_{1}-q_{2}}{6}\left(l_{3}-l_{4}\right)^{3}-k_{1} x_{\mathrm{c} 1}^{4} \\
& \times\left\{\left[\left(\frac{l_{4}+x_{\mathrm{c} 1}}{x_{\mathrm{c} 1}}\right)^{2}+2\left(\frac{l_{4}+x_{\mathrm{c} 1}}{x_{\mathrm{c} 1}}\right)+2\right]\left(\frac{l_{3}+x_{\mathrm{c} 1}}{x_{\mathrm{c} 1}}\right)\right. \\
& \left.-\frac{1}{2}\left(\frac{l_{4}+x_{\mathrm{c} 1}}{x_{\mathrm{c} 1}}+1\right) \times\left(\frac{l_{3}+x_{\mathrm{c} 1}}{x_{\mathrm{c} 1}}\right)^{2}\right\} \mathrm{e}^{-\left(l_{4}+x_{\mathrm{c} 1}\right) / x_{\mathrm{c} 1}} \\
& -k_{4} x_{\mathrm{c} 4}^{4}\left\{4 \mathrm{e}^{-1}\right. \\
+ & \left.2\left(\frac{l_{3}+x_{\mathrm{c} 1}}{x_{\mathrm{c} 1}}\right)\right] \times \mathrm{e}^{-\left(l_{3}+x_{\mathrm{c} 1}\right) / x_{\mathrm{c} 1}}-8 k_{3} x_{\mathrm{c} 3}^{4} \mathrm{e}^{-1} \\
& +\left[\left(\frac{l_{4}-l_{3}-x_{\mathrm{c} 4}}{x_{\mathrm{c} 4}}\right)^{2}-\frac{3}{2}\left(\frac{l_{4}-l_{3}-x_{\mathrm{c} 4}}{x_{\mathrm{c} 4}}\right)+\frac{3}{2}\right] \\
& \left.+\mathrm{e}^{\left(l_{4}-l_{3}-x_{\mathrm{c} 4}\right) / x_{\mathrm{c} 4}}\right\} \\
D_{11} & =-k_{1} x_{\mathrm{c} 1}^{4}\left[\frac{1}{2}\left(\frac{l_{3}+x_{\mathrm{c} 1}}{x_{\mathrm{c} 1}}\right)^{3}+\frac{3}{2}\left(\frac{l_{3}+x_{\mathrm{c} 1}}{x_{\mathrm{c} 1}}\right)^{2}\right.
\end{aligned}
$$

Using (40), (19) can be written in the following form:

$$
M_{l 4}=M_{l 3}+D_{12}=M_{l}+D_{6}+D_{12}
$$

where

$$
\begin{aligned}
D_{12} & =Q_{l 3}\left(l_{3}-l_{4}\right)+\frac{\left(q_{1}-q_{2}\right)}{2}\left(l_{3}-l_{4}\right)^{2} \\
& +k_{1} x_{\mathrm{c} 1}^{3}\left\{\left[\frac{l_{4}+x_{\mathrm{c} 1}}{x_{\mathrm{c} 1}}+2\right] \times \mathrm{e}^{-\left(l_{4}+x_{\mathrm{c} 1}\right) / x_{\mathrm{c} 1}}\right. \\
& -\left\{\left[\left(\frac{l_{3}+x_{\mathrm{c} 1}}{x_{\mathrm{c} 1}}\right)^{2}+2\left(\frac{l_{3}+x_{\mathrm{c} 1}}{x_{\mathrm{c} 1}}\right)+2\right]\right. \\
& \left.\left.-\left(\frac{l_{3}+x_{\mathrm{c} 1}}{x_{\mathrm{c} 1}}+1\right) \times\left(\frac{l_{4}+x_{\mathrm{c} 1}}{x_{\mathrm{c} 1}}\right)\right\} \mathrm{e}^{-\left(l_{3}+x_{\mathrm{c} 1}\right) / x_{\mathrm{c} 1}}\right\} \\
+ & k_{4} x_{\mathrm{c} 4}^{3}\left\{\mathrm{e}^{-1}\left(5+2 \frac{l_{4}-l_{3}-x_{\mathrm{c} 4}}{x_{\mathrm{c} 4}}\right)-(2\right. \\
& \left.\left.-\frac{l_{4}-l_{3}-x_{\mathrm{c} 4}}{x_{\mathrm{c} 4}}\right) \mathrm{e}^{\left(l_{4}-l_{3}-x_{\mathrm{c} 4}\right) / x_{\mathrm{c} 4}}\right\}
\end{aligned}
$$

From (42), (45), and (50), the following equation can be obtained:

$$
j_{1}=-M_{l}\left(l-l_{4}+L\right)+D_{13}
$$

where

$$
D_{13}=D_{7}-D_{10}+D_{11}-\left(l_{3}-l_{4}\right)\left(D_{6}+D_{12}\right)
$$

4.2. Relationship among Integral Constants $d_{1}-d_{6}, j_{1}$, and $j_{2}$. Using (14), (15), and their 1st-3rd derivatives, according to the deflection, dip angle, bending moment, and shear force continuity conditions in (26b), four algebraic equations for $d_{1}-d_{6}$ can be derived. The following can be obtained by solving the equation as follows:

$$
\begin{aligned}
& d_{1}=d_{6}+\frac{q_{1}-q_{2}}{4 \beta^{4} E I}+A_{1} x_{\mathrm{c} 1}^{3}\left(B_{1}+1\right)-A_{2} x_{\mathrm{c} 2}^{3}\left(B_{2}+1\right) \\
& d_{2}=d_{3}+\frac{A_{1} x_{\mathrm{c} 1}\left(B_{1}-1\right)-A_{2} x_{\mathrm{c} 2}\left(B_{2}-1\right)}{2 \beta^{2}} \\
& d_{4}=d_{3}+D_{14} \\
& d_{5}=d_{6}+D_{15}
\end{aligned}
$$

The following has been shown in (54)-(57):

$$
\begin{aligned}
& B_{1}=\frac{4}{1+4 \beta^{4} x_{c 1}^{4}} \\
& B_{2}=\frac{4}{1+4 \beta^{4} x_{c 2}^{4}} \\
& A_{1}=\frac{k_{1}}{E I} \frac{x_{\mathrm{c} 1}^{2} \mathrm{e}^{-1}}{1+4 \beta^{4} x_{\mathrm{c} 1}^{4}} \\
& A_{2}=\frac{k_{2}}{E I} \frac{x_{\mathrm{c} 2}^{2} \mathrm{e}^{-1}}{1+4 \beta^{4} x_{\mathrm{c} 2}^{4}} \\
& D_{14}=\frac{A_{1} x_{\mathrm{c} 1}^{2} B_{1}+A_{2} x_{\mathrm{c} 2}^{2} B_{2}}{2 \beta} \\
& +\frac{A_{1} x_{\mathrm{c} 1}\left(B_{1}-1\right)-A_{2} x_{\mathrm{c} 2}\left(B_{2}-1\right)}{2 \beta^{2}} \\
& +\frac{A_{1}\left(B_{1}-2\right)+A_{2}\left(B_{2}-2\right)}{4 \beta^{3}} \\
& D_{15}=\frac{q_{1}-q_{2}}{4 \beta^{4} E I}+A_{1} x_{\mathrm{c} 1}^{3}\left(B_{1}+1\right)-A_{2} x_{\mathrm{c} 2}^{3}\left(B_{2}+1\right) \\
& +\frac{A_{1} x_{\mathrm{c} 1}^{2} B_{1}+A_{2} x_{\mathrm{c} 2}^{2} B_{2}}{2 \beta} \\
& -\frac{A_{1}\left(B_{1}-2\right)+A_{2}\left(B_{2}-2\right)}{4 \beta^{3}}
\end{aligned}
$$

Using the 1st-3rd derivatives of (15) and (20), according to the first four conditions in (26c), four algebraic equations for $d_{3}-d_{6}, j_{1}, j_{2}, M_{l 4}=M_{l}+D_{6}+D_{12}$, and $Q_{l 4}$ for $x=l_{4}$ can be derived as follows:

$$
\begin{aligned}
& {\left[d_{3} \sin \left(\beta l_{4}\right) \sinh \left(\beta l_{4}\right)+d_{4} \sin \left(\beta l_{4}\right) \cosh \left(\beta l_{4}\right)\right.} \\
& \left.\quad+d_{5} \cos \left(\beta l_{4}\right) \sinh \left(\beta l_{4}\right)+d_{6} \cos \left(\beta l_{4}\right) \cosh \left(\beta l_{4}\right)\right] \\
& \quad+D_{16}=\frac{j_{2}}{E I}+D_{17}
\end{aligned}
$$




$$
\begin{aligned}
\beta\{ & {\left[\cos \left(\beta l_{4}\right) \sinh \left(\beta l_{4}\right)+\sin \left(\beta l_{4}\right) \cosh \left(\beta l_{4}\right)\right] d_{3} } \\
& +\left[\cos \left(\beta l_{4}\right) \cosh \left(\beta l_{4}\right)+\sin \left(\beta l_{4}\right) \sinh \left(\beta l_{4}\right)\right] d_{4} \\
& +\left[\cos \left(\beta l_{4}\right) \cosh \left(\beta l_{4}\right)-\sin \left(\beta l_{4}\right) \sinh \left(\beta l_{4}\right)\right] d_{5} \\
& \left.+\left[\cos \left(\beta l_{4}\right) \sinh \left(\beta l_{4}\right)-\sin \left(\beta l_{4}\right) \cosh \left(\beta l_{4}\right)\right] d_{6}\right\} \\
& -D_{18}=\frac{j_{1}}{E I}+D_{19} \\
2 \beta^{2} & {\left[d_{3} \cos \left(\beta l_{4}\right) \cosh \left(\beta l_{4}\right)+d_{4} \cos \left(\beta l_{4}\right) \sinh \left(\beta l_{4}\right)\right.} \\
& \left.-d_{5} \sin \left(\beta l_{4}\right) \cosh \left(\beta l_{4}\right)-d_{6} \sin \left(\beta l_{4}\right) \sinh \left(\beta l_{4}\right)\right] \\
& +D_{20}=\frac{M_{l}}{E I}+\frac{D_{6}}{E I}+\frac{D_{12}}{E I} \\
2 \beta^{3} & \left\{\left[\cos \left(\beta l_{4}\right) \sinh \left(\beta l_{4}\right)-\sin \left(\beta l_{4}\right) \cosh \left(\beta l_{4}\right)\right] d_{3}\right. \\
& +\left[\cos \left(\beta l_{4}\right) \cosh \left(\beta l_{4}\right)-\sin \left(\beta l_{4}\right) \sinh \left(\beta l_{4}\right)\right] d_{4} \\
& -\left[\cos \left(\beta l_{4}\right) \cosh \left(\beta l_{4}\right)+\sin \left(\beta l_{4}\right) \sinh \left(\beta l_{4}\right)\right] d_{5} \\
& \left.-\left[\cos \left(\beta l_{4}\right) \sinh \left(\beta l_{4}\right)+\sin \left(\beta l_{4}\right) \cosh \left(\beta l_{4}\right)\right] d_{6}\right\} \\
& -D_{21}=-\frac{Q_{l 4}}{E I}
\end{aligned}
$$

The following has been shown in (61)-(64):

$$
\begin{aligned}
D_{16} & =\frac{q_{1}}{4 \beta^{4} E I}+A_{1 l 4} x_{\mathrm{c} 1}^{3}\left[B_{1}+\frac{l_{4}}{x_{\mathrm{c} 1}}+1\right] \\
D_{17} & =\frac{k_{1} x_{\mathrm{c} 1}^{5}}{E I}\left[-\frac{1}{3}\left(\frac{l_{4}+x_{\mathrm{c} 1}}{x_{\mathrm{c} 1}}\right)^{4}-\frac{5}{6}\left(\frac{l_{4}+x_{\mathrm{c} 1}}{x_{\mathrm{c} 1}}\right)^{3}\right. \\
& \left.-\left(\frac{l_{4}+x_{\mathrm{c} 1}}{x_{\mathrm{c} 1}}\right)^{2}+\frac{l_{4}+x_{\mathrm{c} 1}}{x_{\mathrm{c} 1}}+4\right] \mathrm{e}^{-\left(l_{3}+x_{\mathrm{c} 1}\right) / x_{\mathrm{c} 1}} \\
& -\frac{k_{4} x_{\mathrm{c} 4}^{5}}{E I}\left[-\frac{1}{3}\left(\frac{l_{4}-l_{3}-x_{\mathrm{c} 4}}{x_{\mathrm{c} 4}}\right)^{4}\right. \\
& +\frac{5}{6}\left(\frac{l_{4}-l_{3}-x_{\mathrm{c} 4}}{x_{\mathrm{c} 4}}\right)^{3}-\left(\frac{l_{4}-l_{3}-x_{\mathrm{c} 4}}{x_{\mathrm{c} 4}}\right)^{2} \\
& \left.-\left(\frac{l_{4}-l_{3}-x_{\mathrm{c} 4}}{x_{\mathrm{c} 4}}\right)+4\right] \times \mathrm{e}^{\left(l_{4}-l_{3}-x_{\mathrm{c} 4}\right) / x_{\mathrm{c} 4}} \\
D_{18} & =A_{114} x_{\mathrm{c} 1}^{2}\left[B_{1}+\frac{l_{4}}{x_{\mathrm{c} 1}}\right] \\
& -\frac{k_{4} x_{\mathrm{c} 4}^{4}}{E I}\left[-\frac{1}{2}\left(\frac{l_{4}-l_{3}-x_{\mathrm{c} 4}}{x_{\mathrm{c} 4}}\right)^{3}\right. \\
D_{19} & =-\frac{k_{1} x_{\mathrm{c} 1}^{4}}{E I}\left[\frac{1}{2}\left(\frac{l_{4}+x_{\mathrm{c} 1}}{x_{\mathrm{c} 1}}\right)^{3}+\frac{3}{2}\left(\frac{l_{4}+x_{\mathrm{c} 1}}{x_{\mathrm{c} 1}}\right)^{2}\right. \\
& \left.3\left(\frac{l_{4}+x_{\mathrm{c} 1}}{x_{\mathrm{c} 1}}\right)+3\right] \mathrm{e}^{-\left(l_{4}+x_{\mathrm{c} 1}\right) / x_{\mathrm{c} 1}}
\end{aligned}
$$

$$
\begin{aligned}
+ & \left.\frac{3}{2}\left(\frac{l_{4}-l_{3}-x_{\mathrm{c} 4}}{x_{\mathrm{c} 4}}\right)^{2}-3\left(\frac{l_{4}-l_{3}-x_{\mathrm{c} 4}}{x_{\mathrm{c} 4}}\right)+3\right] \\
\cdot \mathrm{e}^{\left(l_{4}-l_{3}-x_{\mathrm{c} 4}\right) / x_{\mathrm{c} 4}} & \\
D_{20} & =A_{114} x_{\mathrm{c} 1}\left[B_{1}+\frac{l_{4}}{x_{\mathrm{c} 1}}-1\right] \\
D_{21} & =A_{1 l 4}\left[B_{1}+\frac{l_{4}}{x_{\mathrm{c} 1}}-2\right] \\
A_{1 l 4} & =\frac{k_{1}}{E I} \frac{x_{\mathrm{c} 1}^{2}}{1+4 \beta^{4} x_{\mathrm{c} 1}^{4}} \mathrm{e}^{-\left(l_{4}+x_{\mathrm{c} 1}\right) / x_{\mathrm{c} 1}}
\end{aligned}
$$

4.3. Determination of $c_{1}-c_{4}, d_{1}-d_{6}, g_{1}, g_{2}, j_{1}, j_{2}$, and $M_{1}$. By substituting $j_{1}=-M_{l}\left(l-l_{4}+L\right)+D_{13}$ in (52) into (62) and adding to (63) to eliminate $M_{l}$, the following equation can be obtained:

$$
\begin{aligned}
& {\left[\cos \left(\beta l_{4}\right) \sinh \left(\beta l_{4}\right)+\sin \left(\beta l_{4}\right) \cosh \left(\beta l_{4}\right)\right.} \\
& \left.\quad+2 \beta\left(l-l_{4}+L\right) \cos \left(\beta l_{4}\right) \cosh \left(\beta l_{4}\right)\right] d_{3} \\
& \quad+\left[\cos \left(\beta l_{4}\right) \cosh \left(\beta l_{4}\right)+\sin \left(\beta l_{4}\right) \sinh \left(\beta l_{4}\right)\right. \\
& \left.\quad+2 \beta\left(l-l_{4}+L\right) \cos \left(\beta l_{4}\right) \sinh \left(\beta l_{4}\right)\right] d_{4} \\
& \quad+\left[\cos \left(\beta l_{4}\right) \cosh \left(\beta l_{4}\right)-\sin \left(\beta l_{4}\right) \sinh \left(\beta l_{4}\right)\right. \\
& \left.\quad-2 \beta\left(l-l_{4}+L\right) \sin \left(\beta l_{4}\right) \cosh \left(\beta l_{4}\right)\right] d_{5} \\
& \quad+\left[\cos \left(\beta l_{4}\right) \sinh \left(\beta l_{4}\right)-\sin \left(\beta l_{4}\right) \cosh \left(\beta l_{4}\right)\right. \\
& \left.\quad-2 \beta\left(l-l_{4}+L\right) \sin \left(\beta l_{4}\right) \sinh \left(\beta l_{4}\right)\right] d_{6}=D_{22}
\end{aligned}
$$

where

$$
\begin{aligned}
D_{22}= & \frac{\left(l-l_{4}+L\right)\left(D_{6}+D_{12}\right)+D_{13}}{\beta E I}+\frac{D_{18}+D_{19}}{\beta} \\
& -\frac{\left(l-l_{4}+L\right)}{\beta} D_{20}
\end{aligned}
$$

$Q_{14}$ and $D_{22}$ are known, and $d_{4}$ and $d_{5}$ can be expressed as $d_{3}$ and $d_{6}$ according to (56) and (57); therefore, (72) and (64) form a linear equation of two unknowns $d_{3}$ and $d_{6}$, and $d_{3}$ and $d_{6}$ can be solved as follows:

$$
\begin{aligned}
& d_{3}=\frac{b_{1} a_{22}-b_{2} a_{12}}{a_{11} a_{22}-a_{12} a_{21}}, \\
& d_{6}=\frac{a_{11} b_{2}-a_{21} b_{1}}{a_{11} a_{22}-a_{12} a_{21}}
\end{aligned}
$$

where

$$
\begin{aligned}
a_{11} & =\mathrm{e}^{\beta l_{4}}\left[\cos \left(\beta l_{4}\right)+\sin \left(\beta l_{4}\right)\right. \\
& \left.+2 \beta\left(l-l_{4}+L\right) \cos \left(\beta l_{4}\right)\right]
\end{aligned}
$$




$$
\begin{aligned}
a_{12} & =\mathrm{e}^{\beta l_{4}}\left[\cos \left(\beta l_{4}\right)-\sin \left(\beta l_{4}\right)\right. \\
& \left.-2 \beta\left(l-l_{4}+L\right) \sin \left(\beta l_{4}\right)\right] \\
a_{21} & =\mathrm{e}^{\beta l_{4}}\left[\cos \left(\beta l_{4}\right)-\sin \left(\beta l_{4}\right)\right] \\
a_{22} & =-\mathrm{e}^{\beta l_{4}}\left[\cos \left(\beta l_{4}\right)+\sin \left(\beta l_{4}\right)\right] \\
b_{1} & =D_{22}-\left[\cos \left(\beta l_{4}\right) \cosh \left(\beta l_{4}\right)+\sin \left(\beta l_{4}\right) \sinh \left(\beta l_{4}\right)\right. \\
& \left.+2 \beta\left(l-l_{4}+L\right) \cos \left(\beta l_{4}\right) \sinh \left(\beta l_{4}\right)\right] D_{14} \\
& +\left[\sin \left(\beta l_{4}\right) \sinh \left(\beta l_{4}\right)-\cos \left(\beta l_{4}\right) \cosh \left(\beta l_{4}\right)\right. \\
& \left.+2 \beta\left(l-l_{4}+L\right) \sin \left(\beta l_{4}\right) \cosh \left(\beta l_{4}\right)\right] D_{15} \\
b_{2} & =\frac{D_{21} E I-Q Q_{14}}{2 \beta^{3} E I}+\left[\sin \left(\beta l_{4}\right) \sinh \left(\beta l_{4}\right)\right. \\
& \left.-\cos \left(\beta l_{4}\right) \cosh \left(\beta l_{4}\right)\right] D_{14}+\left[\sin \left(\beta l_{4}\right) \sinh \left(\beta l_{4}\right)\right. \\
& \left.+\cos \left(\beta l_{4}\right) \cosh \left(\beta l_{4}\right)\right] D_{15}
\end{aligned}
$$

The right-hand terms of (75)-(80) are known; therefore, $d_{1}-d_{6}$ can be determined from (74) and (54)-(57). By substituting $d_{3}-d_{6}$ into (61) $-(63), j_{1}, j_{2}$, and $M_{l}$ can be determined; $M_{l 4}, j_{1}, j_{2}$, and $M_{l 3}$ can be further determined from (50), (44), (45), and (40). Furthermore, using (29) and (32), $c_{3}$ and $c_{1}$ can be determined. Then, using (34) and (33), $c_{2}$ and $c_{4}$ can be determined. All these finally determine the deflection (14) and (15) of an elastic foundation beam, deflection (20) and (21) of a rock beam in the hardened and softened zones of coal seam, and deflection (20) and (21) of a rock beam in goaf.

\section{Method to Determine the Maximum Support Pressure $f_{c 3}$}

The values of $f_{\mathrm{c} 3}$ and $f_{\mathrm{c} 4}$ are critical parameters after introducing the softened and hardened zones of coal seam. Eq. (10) $f_{c 4}=f_{c 3}-q_{2}$ provides the relationship between both these parameters. In a specific calculation, the value of $f_{c 3}$ was empirically "determined", and the criterion of such "determination" was to ensure the continuity of the counterforce of rock beam by coal seam at the junction between the elastic and hardened zones. The accurate method to determine $f_{\mathrm{c} 3}$ is given as follows.

The last condition in (26c) is defined by

$$
\text { A: } E I y_{21}^{(4)}\left(l_{4}\right)=E I y_{22}^{(4)}\left(l_{4}\right)
$$

By comparing (13) and (16), (81) indicates the continuity of the sum of all the vertical distributed forces, including the counterforce of coal seam, on the rock beam at the junction between the elastic and hardened zones of coal seam $\left(x=l_{4}\right)$ shown in Figure 4. Notice that $\beta=[C /(4 E I)]^{1 / 4}$ in (12) and $k_{3}=f_{\mathrm{c} 3} \mathrm{e} / x_{\mathrm{c} 3}$ in (6). By substituting (13) and (16) into (81), the following relationship can be obtained:

$$
C y_{21}\left(l_{4}\right)=F_{4}\left(l_{4}\right)=q_{2}+f_{4}\left(l_{4}\right)
$$

The left-hand term of (82) is the counterforce of coal seam in the elastic zone on the left side of $x=l_{4}$ that is applied on the rock beam, while the right-hand term is the counterforce of coal seam in the hardened zone on the right side of $x=l_{4}$ that is applied on the rock beam. Equation (82) clarifies the issue in the calculation that the continuity of the counterforce of the coal seam at the junction between the elastic and hardened zones on the rock beam after the introduction of the hardened zone of coal seam. By substituting (7) and (10) into (82) and using (9), the right-hand term of (82) can be expressed as the maximum support pressure $f_{\mathrm{c} 3}$ as follows:

$$
C y_{21}\left(l_{4}\right)=F_{4}\left(l_{4}\right)=q_{2}+2 \mathrm{e}^{-1}\left(f_{c 3}-q_{2}\right)
$$

The figure of $E I y^{(4)}(x)$ is named as onbeam vertical distributed force curve. Equation (83) shows that the continuity condition of the counterforce of coal seam at the junction between the elastic and hardened zones $\left(x=l_{4}\right)$ can be expressed as $f_{\mathrm{c} 3}$. Thus, method A used for determining the value of $f_{\mathrm{c} 3}$ was obtained using (81): the value of $f_{\mathrm{c} 3}$ to ensure the continuity of curve $E I y^{(4)}(x)$ at $x=l_{4}$ is the accurate value of $f_{c 3}$ for the continuity of support pressure (or counterforce) of coal seam at the junction between the elastic and hardened zones $\left(x=l_{4}\right)$ on rock beam.

The following example can be used to illustrate the application of method A to determine the value of $f_{\mathrm{c} 3}$. If $q_{2}=7 \mathrm{MN} / \mathrm{m}, x_{\mathrm{c} 1}=8 \mathrm{~m}, x_{\mathrm{c} 2}=13 \mathrm{~m}, x_{\mathrm{c} 3}=8.6 \mathrm{~m}$, and $x_{\mathrm{c} 4}=$ $2 \mathrm{~m}$ and the foundation constant of elastic zone of coal seam $C=0.4 \mathrm{GPa}$ and elastic modulus of roof $E=25 \mathrm{GPa}$, together with the equations and parameters described in Section 2, by substituting (15) and (20) into $E I y^{(4)}(x)$ in (13) and (16), the distribution curve chart of $E I y^{(4)}(x)$ can be plotted by Matlab for the elastic zone $\left[0, l_{4}\right]$ and the hardened zone $\left[l_{4}, l_{3}\right]$ of coal seam, as shown in Figure 9.

Figure 9 shows that when the maximum support pressure $f_{c 3}$ in the softened zone of coal seam is $7 \times 1.7$ or $7 \times 1 \mathrm{MN} / \mathrm{m}$, $E I y^{(4)}(x)$ distribution curves $a$ and $b$ are discontinuous at the junction between the elastic and hardened zones of coal seam at $x=8 \mathrm{~m}$, while for $f_{\mathrm{c} 3}=7 \times 1.435272=10.046906 \mathrm{MN} / \mathrm{m}$, $E I y^{(4)}(x)$ distribution curve 1 is continuous at the junction at $x=8 \mathrm{~m}$.

\section{Numerical Examples}

An increase in the advanced distance of working face or hanging roof area of goaf changes the parameters of the softened zone of coal seam. For instance, as the hanging roof distance increases, the overall load above the coal seam increases, and the maximum support pressure increases (Figure 2), but the residual strength of coal seam at coal wall $f_{3}(l)$ gradually decreases. The depth of the softened zone of coal seam increases (i.e., $l-l_{3}$ increased).

As mentioned above, let the mean load in Figure $4 q_{2}=$ $7 \mathrm{MN} / \mathrm{m}, x_{\mathrm{c} 1}=8 \mathrm{~m}$, and $x_{\mathrm{c} 2}=13 \mathrm{~m}$; concerning the rock beam with a hanging roof distance of $L=20 \mathrm{~m}$, assuming that as the working face advances each $2 \mathrm{~m}, x_{\mathrm{c} 3}$ in (5) decreases from $8.6 \mathrm{~m}$ by $0.3 \mathrm{~m}$. Using the relevant equations described in Sections 2 and 3 and the integral constants described in Section 4, concerning the rock beam in the goaf with a hanging roof distance of $L=20,22,24 \mathrm{~m}, l=18 \mathrm{~m}, l_{3}=10$ 


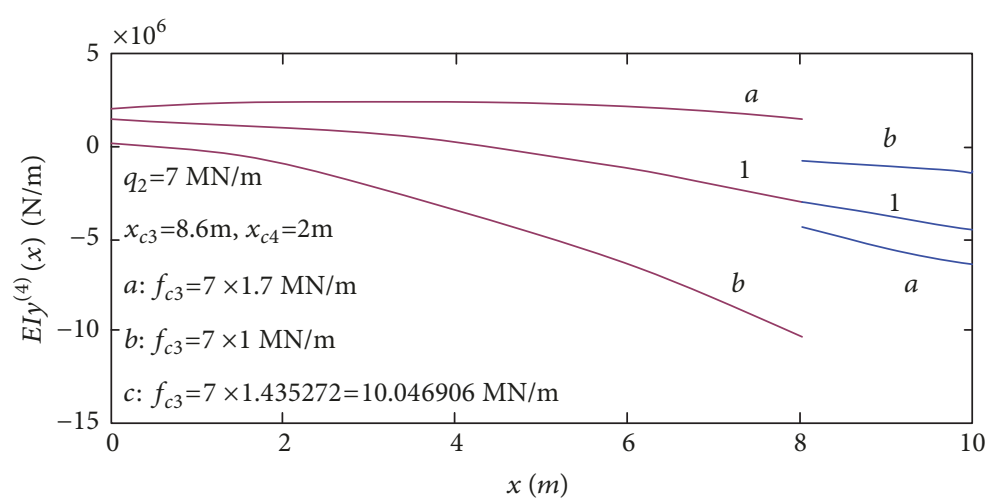

Figure 9: The $E I y^{(4)}(x)$ curves at with different $f_{\mathrm{c} 3}$ values.

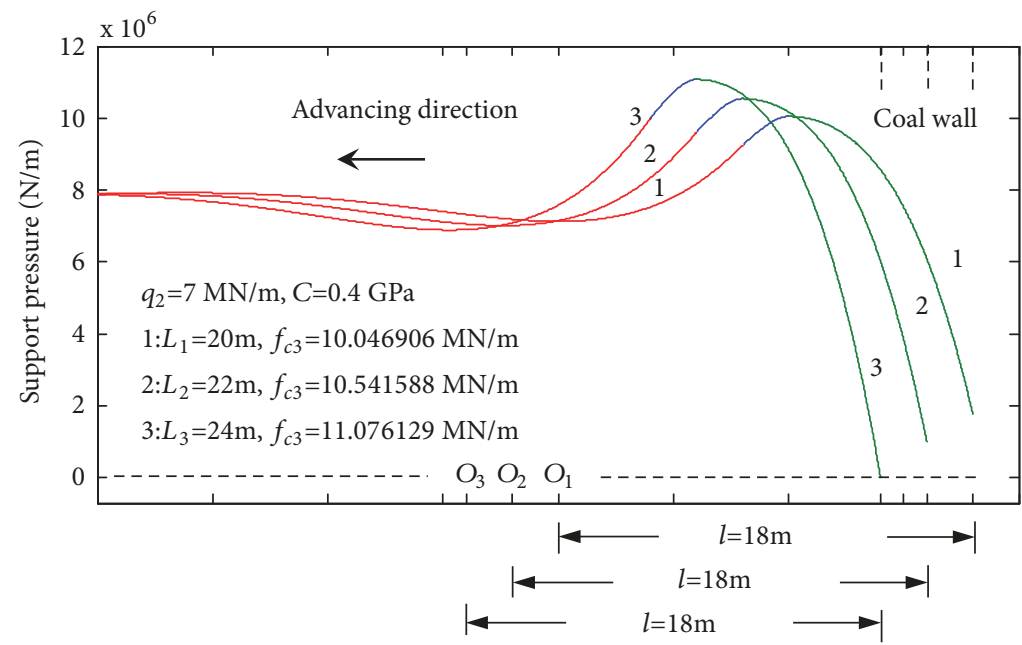

FIGURE 10: Support pressure curves of coal seam with the increasing of the distance of overhang roof.

$\mathrm{m}$ (i.e., the depth of softened zone remains constant, $l-l_{3}=8$ $\mathrm{m}), x_{\mathrm{c} 3}=8.6,8.3,8 \mathrm{~m}, x_{\mathrm{c} 4}=2 \mathrm{~m}$, the elastic modulus of roof is $E=25 \mathrm{GPa}$, the elastic foundation constant $C=0.4 \mathrm{GPa}$, $p_{o}=0.9 \mathrm{MN} / \mathrm{m}$, and $p_{k}=1.2 p_{o}$. According to (13), (15), and (16) and the method introduced in Section 5, after a couple of trial calculations, the maximum support pressure of coal seam was found to be accurate to the sixth decimal place:

$$
f_{\mathrm{c} 3}=10.046906,10.541588,11.076129 \mathrm{MN} / \mathrm{m}
$$

Substituting this set of $f_{\mathrm{c} 3}$ values (5), the support pressure of coal seam at the coal wall can be obtained as follows:

$$
f_{3}(l) \approx 1.78,1.00,0 \mathrm{MN} / \mathrm{m}
$$

Equations (84) and (85) show that as the hanging roof distance of goaf $L$ increases, the maximum support pressure of coal seam $f_{\mathrm{c} 3}$ increases, and the residual strength of coal seam at coal wall $f_{3}(l)$ decreases. When $L=24 \mathrm{~m}$, the residual strength of coal seam $f_{3}(l) \approx 0$.

Based on the $f_{\mathrm{c} 3}$ values listed in (84) and the condition of constant depth of the softened zone of coal seam ( $l-$ $l_{3}$ ) $=8 \mathrm{~m}$, numerical examples for the support roof model of elastic, hardened, and softened zones are shown in Figure 4. The results were compared with the roof bending moments without considering the hardening of coal seam [20] (coal seam can be divided into two zones: elastic and softened zones).

6.1. Support Pressure of Coal Seam as Hanging Roof Distance $L$ Increases. Curves 1, 2, and 3 in Figure 10 show the support pressure curves of softened, hardened, and elastic zones of coal seam when the working face advances or the hanging roof distance of goaf increases. They were plotted according to $f_{\mathrm{c} 3}$ values in (84) and (5), (7), (14), and (15). To compare with the support pressures in Figures 1 and 2, the positive direction of support pressure of coal seam is shown upward in the chart. Figure 10 shows that the curves 1,2 , and 3 are smooth and continuous at the junction between the hardened and softened zones of coal seam (location of support pressure peak) and the junction between two elastic zones $\left(o_{1}, o_{2}\right.$, and $o_{3}$ ). In Figure 10, as the hanging roof distance $L$ increases (the total load above the corresponding coal seam increases), the maximum support pressure of coal seam $f_{\mathrm{c} 3}$ gradually increases, while the residual strength of coal seam at the coal wall $f_{3}(l)$ decreases (among which $f_{3}(l)$ of curve 3 tends to be close to 0$)$, similar to the variation trend of support curve shown in Figure 2. 


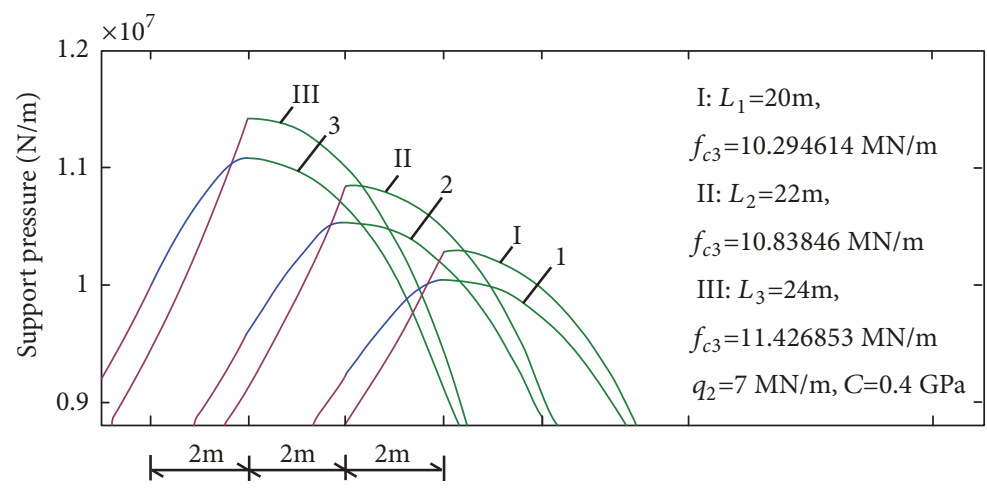

FIGURE 11: Enlarged drawings at peak part of support pressure with the increasing of the distance of overhang roof.

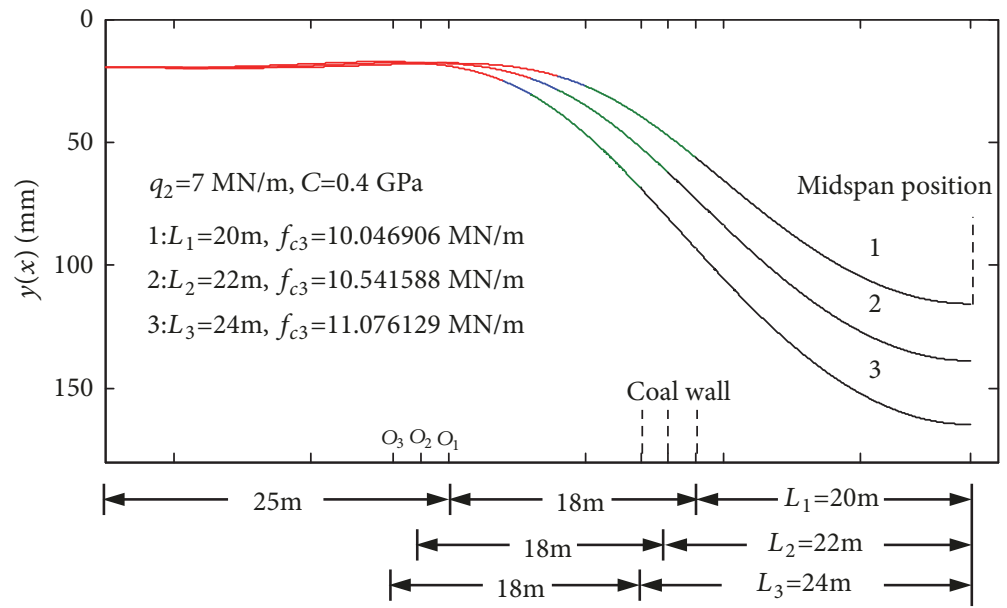

FIGURE 12: Deflection curves of rock beam with the increasing of the distance of overhang roof.

The curves 1, 2, and 3 in Figure 11 are magnified curves corresponding to the range of support pressure peaks in Figure 10. The support pressure curves I, II, and III are also shown in the chart without considering coal seam hardening according to the literature [20] under the same conditions of overlying load and hanging roof distance (curves are not smooth at the junction between the softened and elastic zones). The peak values of curves I, II, and III in Figure 11 are defined as follows:

$$
f_{\mathrm{c} 3}=10.294614,10.838460,11.076129 \mathrm{MN} / \mathrm{m}
$$

They were obtained based on the continuity conditions of counterforces of coal seam at the junction between the elastic and softened zones according to literature [20]. Figure 11 shows that the peak values $f_{\mathrm{c} 3}$ of curves I, II, and III are higher than those of curves 1,2 , and 3 ; however, their plumpness is inferior to that of curves 1,2 , and 3 .

Figure 11 also shows that owing to the parameter of hardened zone of coal seam $x_{\mathrm{c} 4}=2 \mathrm{~m}$, the hardened zones of support pressure curves 1, 2, and 3 for three zones are all $2 \mathrm{~m}$ (see blue line segments in Figure 11; red and green line segments in Figure 11 denote the ranges of the elastic and softened zones, respectively).
6.2. Deflection of Rock Beam as Hanging Roof Distance L Increases. Figure 12 shows the deflection curves of rock beam with the increase in hanging roof distance corresponding to the support pressure curves of coal seam in Figure 10. Curves 1,2 , and 3 ahead of $x=-25 \mathrm{~m}$ tend to be $19 \mathrm{~mm}$, close to the condition of $y(-\infty)=q_{2} / C=17.5 \mathrm{~mm}$ in (26a). A horizontal tangential line exists on the deflection curve of rock beam at the midspan position of the goaf, where the location is $(l+L)=38,40,42 \mathrm{~m}$, satisfying the condition of $y_{12}^{\prime}(l+L)=0$ in (26g). Besides, $y_{12}(l+L)=116,139,165 \mathrm{~mm}$, i.e., each increase of $2 \mathrm{~m}$ of the hanging roof distance at this advancing phase results in an increase of (23-26) $\mathrm{mm}$ of the deflection of rock beam at goaf midspan.

Additionally, the support pressure parts in $(-\infty, 0]$ and $\left(0, l_{4}\right]$ of both sides of the three origins $o_{1}, o_{2}$, and $o_{3}$ in Figure 10 are shown by $C \cdot y_{2}(x)$ and $C \cdot y_{21}(x)$. These are the deflections of rock beam $y_{2}(x)$ and $y_{21}(x)$ of the corresponding segments in Figure 12 by multiplying foundation constant $C=0.4 \mathrm{GPa}$, respectively.

Figure 13 shows the magnified chart of the deflections of rock beam at the junction between the elastic and hardened zones (red and blue lines) of coal seam in Figure 12, where the horizontal axis of intersection between three vertical dashed lines whose intervals between the neighboring lines are 2 


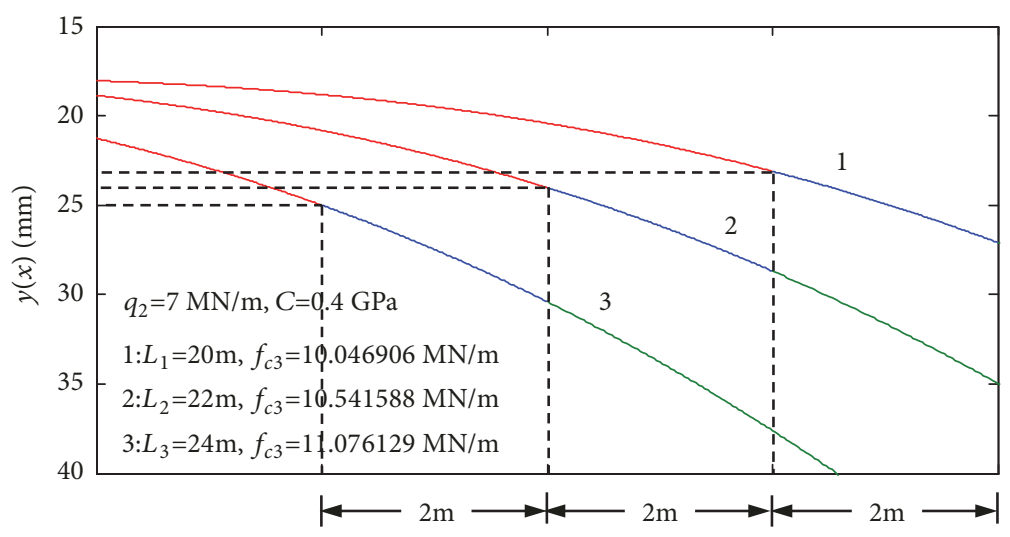

FIgURE 13: Enlarged drawings of rock beam deflection curves at the junction between elastic area and hardening area of coal seam.

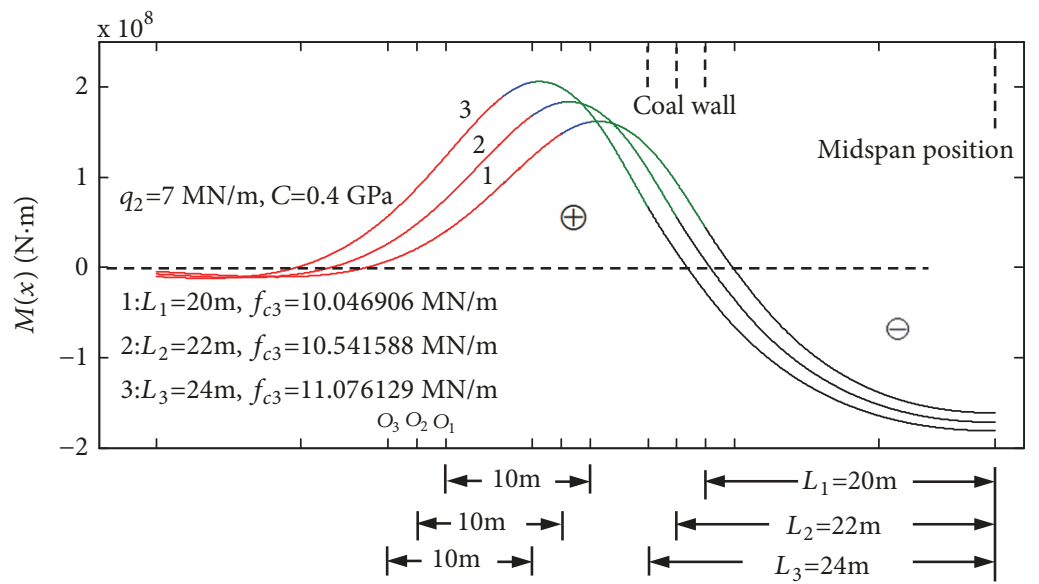

FIGURE 14: Bending moment curves of rock beam with the increasing of the distance of overhang roof.

$\mathrm{m}$ and curves 1,2 , and 3 are 23.10, 24.01 and $25.00 \mathrm{~mm}$. By multiplying these three values by the elastic foundation constant $C=0.4 \mathrm{GPa}$, the counterforces or the support pressures of the coal seam on the right end of the elastic zone can be obtained: $C \cdot y_{21}\left(l_{4}\right) \approx 9.240,9.604,10.00 \mathrm{MN} / \mathrm{m}$. By substituting $q_{2}$ and $f_{\mathrm{c} 3}$ in Figures 12 and 13 into the right term of (83), the support pressure on the left end of the hardened zone of coal seam can be computed: $F_{4}\left(l_{4}\right) \approx 9.242$, 9.606, 9.999 $\mathrm{MN} / \mathrm{m}$, almost equal to the support pressures on the right end of the elastic zone of coal seam, indicating the validity of (82) for the continuity of counterforce of coal seam on rock beam at the junction between the elastic and hardened zones of coal seam described in Section 5 and the sufficient accuracy of the maximum support pressure $f_{\mathrm{c} 3}$ given in (86).

6.3. Bending Moment of Rock Beam as Hanging Roof Distance $L$ Increases. Figure 14 shows the bending moment curves of rock beam corresponding to the deflection curves shown in Figure 11. The curves tend to 0 ahead of $x=-25 \mathrm{~m}$, and a horizontal tangential line $M_{12}^{\prime}(l+L)=0$ exists at the midspan of goaf on each of the curves. Based on (28) for bending moment and shear force, it shows that the shearing force of rock beam on the midspan cross-section of goaf satisfies
$Q_{12}(l+L)=0$, conforming to the boundary condition of (26g). The peak values of bending moment of curves 1,2 , and 3 ahead of coal wall are $M_{\max }(\widehat{x})=1.62 \times 10^{8}, 1.83 \times 10^{8}$, $2.06 \times 10^{8} \mathrm{~N} \cdot \mathrm{m}$, and the values of bending moment at the midspan of goaf are $M_{12}(L+l)=-1.61 \times 10^{8},-1.72 \times 10^{8}$, and $-1.81 \times 10^{8} \mathrm{~N} \cdot \mathrm{m}$; i.e., the maximum bending moment of rock beam ahead of coal wall remains higher than the absolute value of bending moment at the midspan of goaf.

Curves 1, 2, and 3 in Figure 15 show the magnified chart for peak parts of the bending moment curves of rock beam shown in Figure 14. Curves 1, 2, and 3 achieved their peak values of bending moment $M_{\max }(\widehat{x})$ at $\widehat{x}=10.59,10.55,10.51$ $\mathrm{m}$. The position at the junction between the hardened and softened zones of coal seam is $l_{3}=10 \mathrm{~m}$, the abovementioned three $\widehat{x}$ values are all higher than $10 \mathrm{~m}$. Thus, the peaks of the three bending moments of rock beam are located in the softened segment of coal seam (green line segments in Figure 14; the blue and red line segments in Figure 15 are the hardened and elastic ranges of coal seam, respectively). The advanced distance of bending moment peak of rock beam was denoted as $\hat{l}$, and each $\widehat{x}$ value at the coal wall position $l=18 \mathrm{~m}$ was subtracted. The advanced distance of bending moment peak of rock beam $\widehat{l}=l-x \approx 7.41,7.45,7.49 \mathrm{~m}$ can be obtained, indicating that the advanced distance of bending 


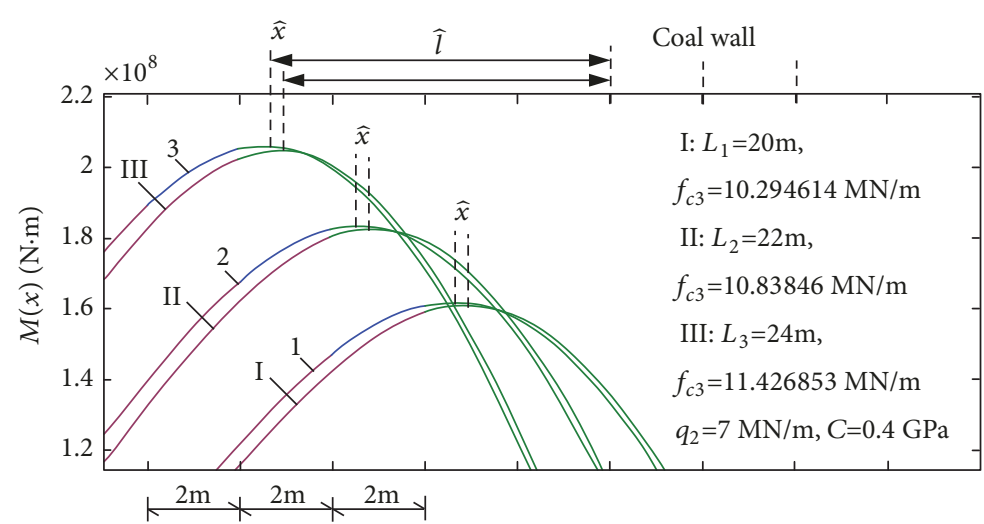

FIGURE 15: Enlarged drawings at peak part of rock beam bending moment with the increasing of the distance of overhang roof.

moment peak of rock beam increases as the hanging roof distance increases.

Curves I, II, and III in Figure 15 show the magnified chart of the bending moment peaks of rock beam corresponding to the two-zone support pressure curves shown in Figure 11. Curves I, II, and III achieved their bending moment peaks at $\widehat{x}=10.86,10.84,10.81 \mathrm{~m}$. By subtracting each $\widehat{x}$ value at the coal wall position $l=18 \mathrm{~m}$, the advanced distance of bending moment peak of rock beam $M_{\max }(\widehat{x})$ can be obtained as $\hat{l}=$ 7.14, 7.16, $7.19 \mathrm{~m}$.

By comparing the $\hat{l}$ values among curves 1,2 , and 3 and curves I, II, III, it was found that the advanced distance of bending moment peak of the support rock beam with elastichardened-softened three-zone coal seam with a hardened zone parameter length of $x_{c 4}=2 \mathrm{~m}$ exceeds those of the support rock beam with elastic-softened two-zone coal seam by about 27,29 and $30 \mathrm{~cm}$. Figure 15 also shows that, under identical conditions of overlying load and hanging roof distance, the peak values of bending moments for the support roof of three zones considering coal seam hardening are slightly higher than those of two zones without considering coal seam hardening.

\section{Numerical Examples of Bending Moment of Roof as Depth of Softened Zone Varies}

Concerning the roof, the mean load is $q_{2}=7 \mathrm{MN} / \mathrm{m}, x_{\mathrm{cl}}=$ $8 \mathrm{~m}$, and $x_{\mathrm{c} 4}=13 \mathrm{~m}$; the length of rock beam is $L=22 \mathrm{~m}$, $l=18 \mathrm{~m}, l_{3}=10.5,10,9.5 \mathrm{~m}$. When the scale parameters of the softened and hardened zones of coal seam are $x_{\mathrm{c} 3}=8.5 \mathrm{~m}$ and $x_{\mathrm{c} 4}=2 \mathrm{~m}$, based on the methods and equations described in Sections 1-5, the peak values of the support pressure of coal seam can be obtained for the depth of softened zone of coal seam $\left(l-l_{3}\right)=7.5,8,8.5 \mathrm{~m}$ :

$$
f_{\mathrm{c} 3}=10.062068,10.387880,10.814946 \mathrm{MN} / \mathrm{m}
$$

Curves 1, 2, and 3 in Figure 16 show the support pressure curves of the softened, hardened, and elastic zones when the depth of the softened zone of coal seam is $\left(l-l_{3}\right)=7.5,8$, $8.5 \mathrm{~m}$, based on the $f_{\mathrm{c} 3}$ values of (87) and (5), (7), (14), and (15). Figure 16 shows that as the depth of the softened zone $\left(l-l_{3}\right)$ (the range denoted by green lines) increases, the peak values $f_{\mathrm{c} 3}$ of the curves increase, while the residual strengths of coal $f_{3}(l)$ at the coal wall gradually decrease, among which the residual strength of curve 3 is $f_{3}(l) \longrightarrow 0$.

Curves 1, 2, and 3 in Figure 17 show the magnified chart of the peak parts of support pressures in Figure 16. This chart also shows the support pressure curves of coal seams I, II, and III for the two-zone relationship of softened and elastic zones with reference to the literature [16] under identical conditions of overlying load and depth of the softened zone of a coal seam. The peak values of curves I, II, and III in Figure 17

$$
f_{\mathrm{c} 3}=10.346857,10.674489,11.112275 \mathrm{MN} / \mathrm{m}
$$

were obtained based on the continuity condition of the counterforce at the junction between the elastic and softened zones according to the literature [20]. Figure 17 shows that the peak values $f_{\mathrm{c} 3}$ of curves I, II, and III are higher than those of curves 1,2 , and 3 , but the plumpness is inferior.

As space is limited, Figure 18 only shows the magnified chart for the peak parts of the bending moment curves of rock beam corresponding to the support pressure curves in Figures 16 and 17. In Figure 18, the peak values of the bending moments for curves 1, 2, and 3 are slightly higher than those of curves I, II, and III. Curves 1, 2, and 3 in Figure 18 reach the peak values of bending moment at $\widehat{x} \approx 11.08,10.64,10.14$ $\mathrm{m}$, and each of $\hat{x}$ is located in the corresponding softened segment of coal seam (each range is denoted by green lines). By subtracting each $\widehat{x}$ value at the coal wall position $l=18 \mathrm{~m}$, the advanced distances of the bending moment peak of rock beam can be obtained as $\widehat{l} \approx 6.92,7.36,7.86 \mathrm{~m}$, i.e., each $0.5 \mathrm{~m}$ increase of the depth of the softened zone of coal seam leads to an increase in the advanced distance of bending moment peak by $\widehat{l}_{2}-\widehat{l}_{1} \approx 44 \mathrm{~cm}$ and $\widehat{l}_{3}-\widehat{l}_{2} \approx 50 \mathrm{~cm}$. Curves I, II, and III in Figure 18 reach the peak values of bending moment at $\widehat{x} \approx 11.38,10.93,10.42 \mathrm{~m}$ corresponding to the advanced distances of bending moment peak of rock beam $\hat{l} \approx 6.62$, $7.07,7.58 \mathrm{~m}$. A comparison shows that, under the same depth condition of the softened zone of a coal seam, the advanced distances of bending moment peak of support rock beam with elastic-hardened-softened three zones are higher than those with elastic-softened two zones by about 30,29 , and $28 \mathrm{~cm}$. 


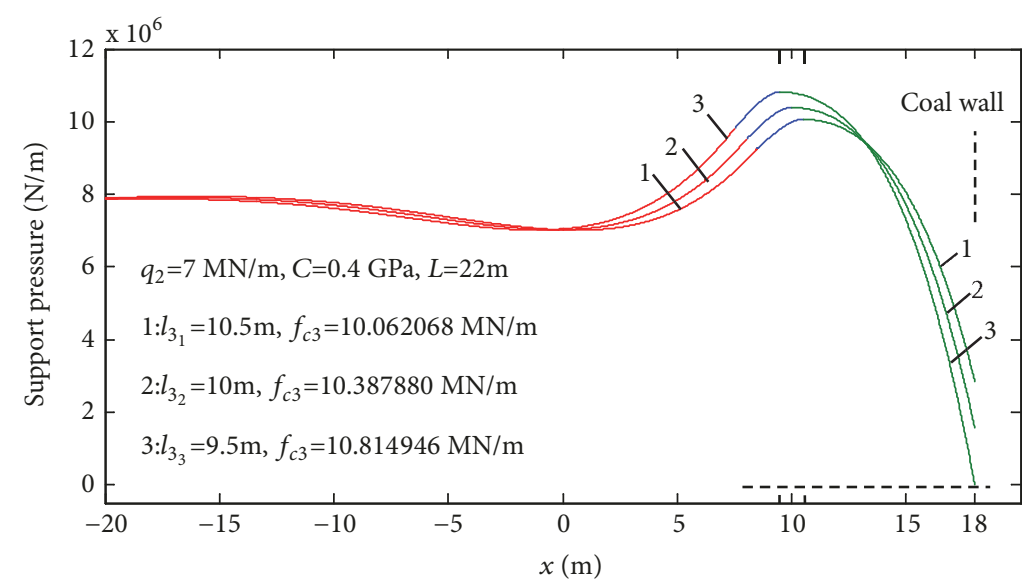

FIGURE 16: Support pressure curves of coal seam for different softening area depths.

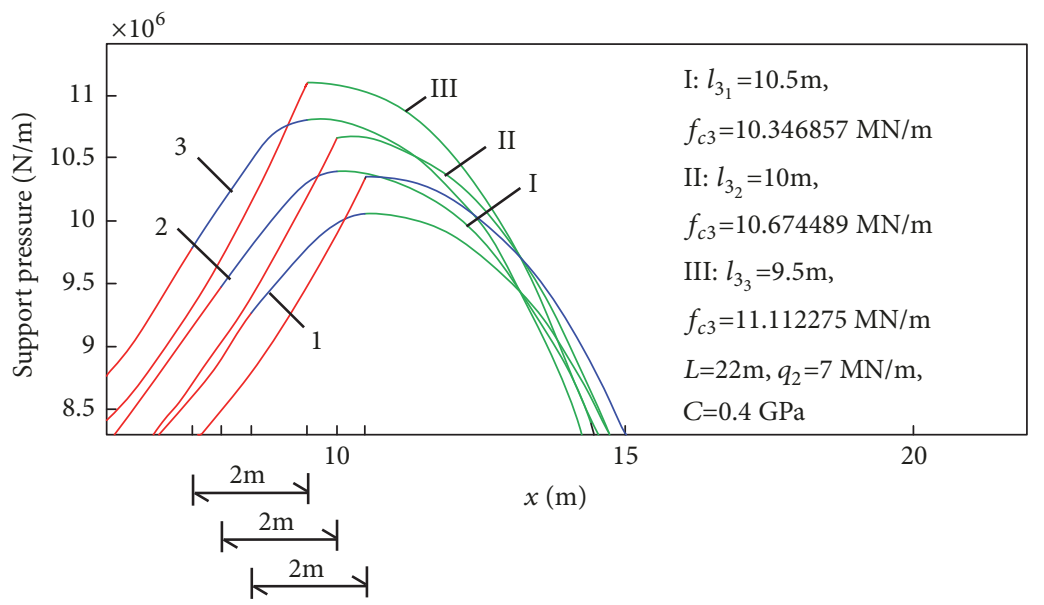

FIGURE 17: Enlarged drawings at peak part of coal seam support pressure for different softening area depths.

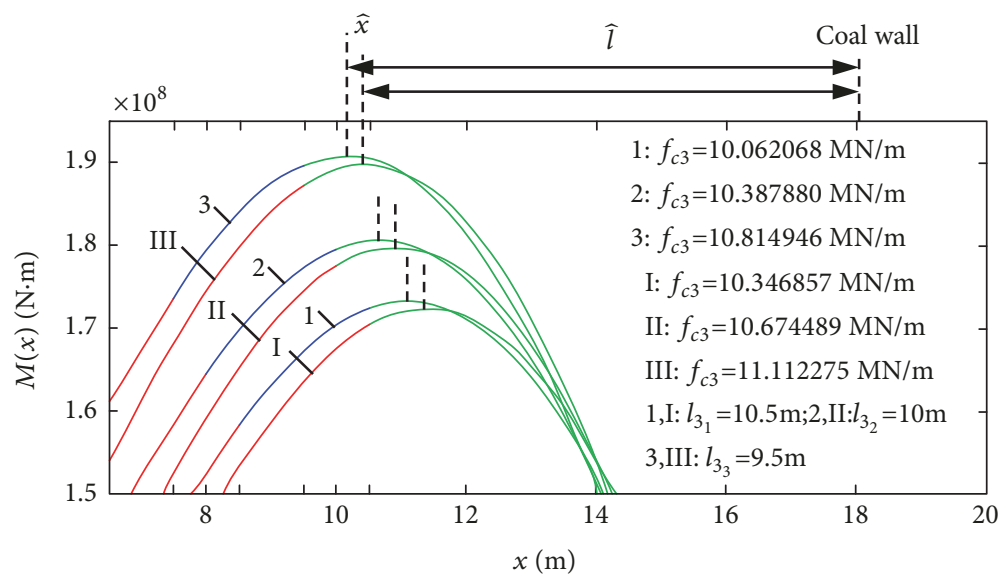

FIGURE 18: Enlarged drawings at peak part of rock beam bending moment for different softening area depths.

\section{Discussion}

8.1. Relationship between Advanced Distance of Bending Moment Peak of Rock Beam and Depth of Softened Zone of Coal Seam. The advanced distance of bending moment peak of a hard roof is directly associated with the advanced fracturing distance of the hard roof. The bending moment peaks shown in Figure 15 in Section 6 and Figure 18 in Section 7 are located slightly behind the softened zone of coal seam or the support pressure peak, consistent with the 


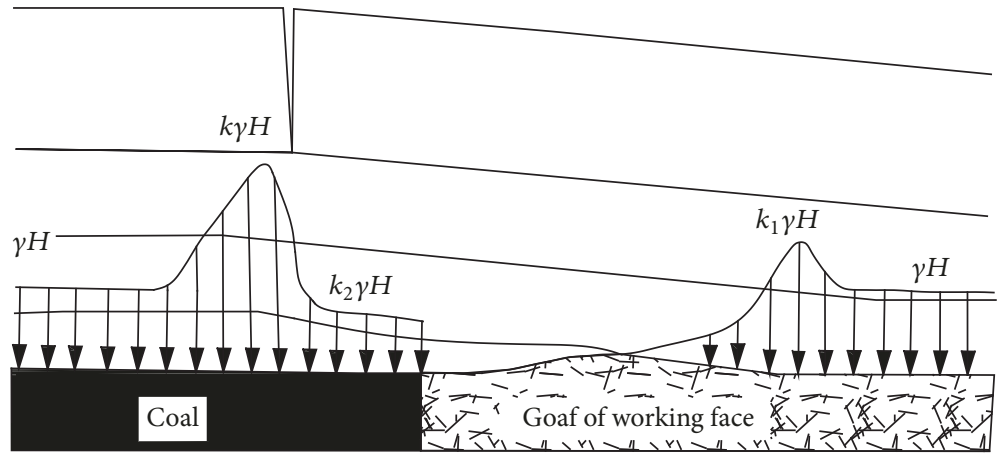

FIGURE 19: The model of double peaks of support pressure [22].

TABLE 1: Engineering example of hard roof fracturing ahead of working face.

\begin{tabular}{|c|c|}
\hline Hard roof of working face & Advanced fracturing distance \\
\hline Old roof of coal mine in western of Xuzhou & About $4 \mathrm{~m}[1]$ \\
\hline Roof of 741003 working face of Muchengjian mine & $5-8 \mathrm{~m}[24]$ \\
\hline Roof of coal seam 2 of Beijing Mining Bureau & About 6m [24] \\
\hline Old roof of coal seam of Xinqiu mine & $6.3 \mathrm{~m}, 8 \mathrm{~m}[23]$ \\
\hline Roof of 8320 working face of Dafeng mine & $9.98 \mathrm{~m}[25]$ \\
\hline Old roof of Sanhejian mine in Xuzhou & About 10m [26] \\
\hline Roof of east 708 working face of Zhangxiaolou mine & $11.56 \mathrm{~m}[25]$ \\
\hline
\end{tabular}

breaking position of main roof located slightly behind the support pressure peak reported by He et al. [22] (Figure 19).

Table 1 shows nine engineering examples of the advanced fracturing distance of a hard roof predicted by the bounce information of a stope roof and proved by exposing the coal rock seam. Table 1 shows that the actual advanced fracturing distance of hard roof has a relatively broad range, where the advanced fracturing distance of East 708 working face roof of Zhang Xiao Lou Coal Mine reaches $11.56 \mathrm{~m}$. In the statistical data provided by Shao [23], the advanced fracturing distance of a hard roof is 3-8 times the working height. The reason for such a relatively broad range of advanced fracturing distance of a hard roof is not further addressed either in the literature [23] or in other literatures related to roof fracture.

The advanced distance of the bending moment peak in Figure 18 described in Section 7 is $\hat{l} \approx 6.92,7.36,7.86$ $\mathrm{m}$, comparable to (6.3-8) $\mathrm{m}$ in the middle of Table 1 . Figure 18 shows that the depth of the softened zone of a coal seam significantly affects the advanced distance of bending moment peak. The measured depth of the softened zone of coal seam in Figure 1 is $15 \mathrm{~m}$, while those on the bending moment curve in Figure 18 are only 7.5, 8, and $8.5 \mathrm{~m}$. If the data of the softened zone of coal seam with a higher depth are used, according to the methods and equations described in Sections 1-5, the calculation results and charts for the advanced distance of bending moment peak of more than 10 $m$ can be acquired.

8.2. Quantitative Relationship between Overlying Load of Rock Beam and Support Pressure of Underlying Coal Seam. Figure 20 shows the shearing force curve of rock beam corresponding to the support pressure curve shown in Figure 16 and the bending moment curve shown in Figure 18.

Figure 20 shows that the shearing force of rock beam on the midspan surface of goaf is 0 , conforming to the condition $Q_{12}(l+L)=0$ in $(26 \mathrm{~g})$. The abscissae for the curves reaching 0 at $11.08,10.64$ and $10.14 \mathrm{~m}$ correspond to those of the peaks of the bending moment curves shown in Figure 18; a peak value of curve appears ahead of coal wall, and the maximum $Q_{l}$ is obtained at the coal wall $(x=18 \mathrm{~m})$. The shear force curves are not smoothly connected at both the ends of roof control area $(x=18 \mathrm{~m}, x=22 \mathrm{~m})$ owing to a sudden change in the distributed force at both the ends of roof control area beneath the rock beam shown in Figure 4, and the consequent bending angle appears at the sudden change place of distributed force in the shear force chart according to the mechanics of materials. The shear force charts of the three curves from the coal wall to the midspan segment $[18,40] \mathrm{m}$ of goaf are identical, because the overlying rock beam loads $q_{1}, f_{1}(x)$, and support forces are identical in this segment and the directed support at the right end of the mechanical model $(x=40 \mathrm{~m})$ in Figure 4 can move upwards or downwards without a vertical counterforce.

Figure 20 shows that the shear force curves tend to be zero in the front segment of $x<-40 \mathrm{~m}$, indicating that the overlying uplift load, hanging roof, and support resistances slightly affect the shear force of rock beam ahead of $x=$ $-40 \mathrm{~m}$. Thus, $x=-40 \mathrm{~m}$ cross-section is treated as the boundary in Figure 4, and to maintain the balance of force in $y$ direction within the rock seam system of front or rear of the cross-section, the shear force of the rock beam $Q(-40) \approx 0$ should be transferred to the other side of the cross-section. Therefore, regarding the isolating body of the entire rock 


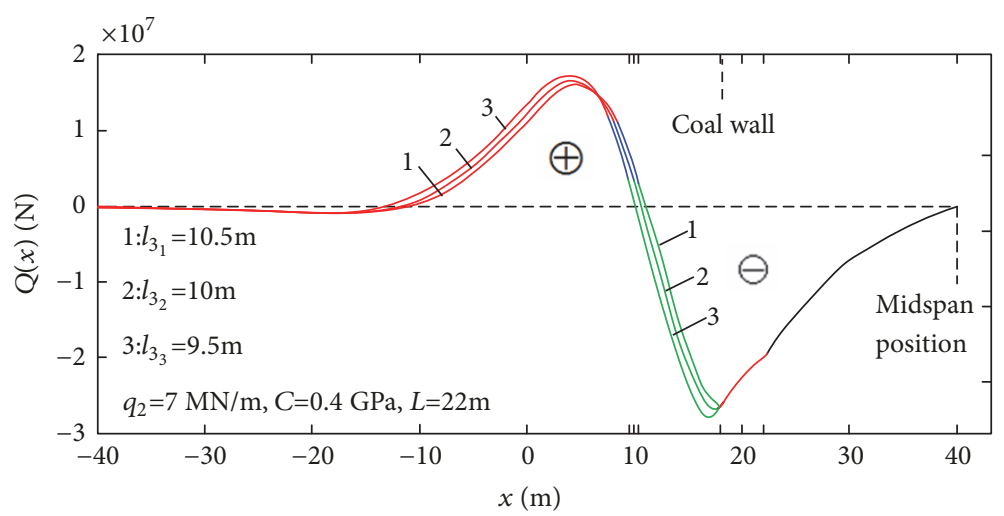

FIGURE 20: Abutment forces curves of coal seam with the increasing of the distance of overhang roof.

seam system in the rear of $x=-40 \mathrm{~m}$ cross-section in Figure 4, the relationship between the vertical loads along the $y$ direction can be expressed as follows:

$$
\begin{aligned}
\sum F_{y} & \approx 0, \\
\text { or } \sum F_{\text {yabove }} & \approx \sum F_{\text {ybelow }}
\end{aligned}
$$

where

$$
\begin{aligned}
\sum F_{\text {yabove }}= & \int_{-40}^{0} f_{2}(x) \mathrm{d} x+q_{2} \times 40+\int_{0}^{l+L} f_{1}(x) \mathrm{d} x \\
& +q_{1} \times(l+L) \\
\sum F_{\text {ybelow }}= & \int_{-40}^{0} C y_{2}(x) \mathrm{d} x+\int_{0}^{l_{4}} C y_{21}(x) \mathrm{d} x \\
& +\int_{l_{4}}^{l_{3}} F_{4}(x) \mathrm{d} x+\int_{l_{3}}^{l} f_{3}(x) \mathrm{d} x+p_{\mathrm{o}} \\
& \times L_{k}+\frac{\left(p_{k}-p_{\mathrm{o}}\right) L_{k}}{2}
\end{aligned}
$$

By substituting the onbeam mean load $q_{2}=7 \mathrm{MPa}, f_{\mathrm{c} 2}=$ $0.22 q_{2}, q_{1}=0.15 \mathrm{MPa}, f_{\mathrm{c} 1}=q_{2}+f_{\mathrm{c} 2}-q_{1}, p_{o}=0.9 \mathrm{MN} / \mathrm{m}$, $p_{k}=1.2 p_{o}, L_{k}=4 \mathrm{~m}$ and $l_{3}=10.5,10,9.5 \mathrm{~m}, l=18 \mathrm{~m}, L=22$ $\mathrm{m}, x_{\mathrm{c} 1}=8 \mathrm{~m}, x_{\mathrm{c} 2}=13 \mathrm{~m}, x_{\mathrm{c} 3}=8.5 \mathrm{~m}, x_{\mathrm{c} 4}=2 \mathrm{~m}, l_{4}=l_{3}-x_{\mathrm{c} 4}$, and $y_{2}(x)$ from $(14), y_{21}(x)$ from (15), $f_{3}(x)$ from $(5), F_{4}(x)$ from (7), and $f_{\mathrm{c} 3}$ values from (87) into (90) and (91), the following expressions can be obtained using Matlab:

$$
\begin{aligned}
& \sum F_{\text {yabove }}=(3.5354+28+13.107+0.6) \times 10^{7} \\
& =45.2424 \times 0^{7} \mathrm{~N} \\
& \sum F_{\text {ybelow }}^{l_{3}=10.5} \\
& =(30.435+6.475+1.9489+5.9945+0.396) \\
& \quad \times 10^{7} \mathrm{~N}=45.2494 \times 10^{7} \mathrm{~N}
\end{aligned}
$$

$$
\begin{aligned}
\sum F_{\text {ybelow }}^{l_{3}=10} & \\
= & (30.333+6.2102+2.0074+6.3023+0.396) \\
& \times 10^{7} \mathrm{~N}=45.2489 \times 10^{7} \mathrm{~N} \\
\sum F_{\text {ybelow }}^{l_{3}=9.5} & \\
= & (30.207+5.9585+2.0839+6.603+0.396) \\
\quad & \times 10^{7} \mathrm{~N}=45.2484 \times 10^{7} \mathrm{~N}
\end{aligned}
$$

The relative error between each $\sum F_{y \text { below }}$ in (93)-(95) and $\sum F_{\text {yabove }}$ in (92) is less than $2 / 10000 . \sum F_{\text {yabove }}$ is the area enveloped by the curves of overlying loads $F_{2}(x)=q_{2}+$ $f_{2}(x)$ and $F_{1}(x)=q_{1}+f_{1}(x)$ in $[-40, l+L] \mathrm{m}$ segment of rock beam and the horizontal axis in Figure 4, and it is the sum of the distributed loads of rock beam in this segment. $\sum F_{y \text { below }}$ in (93)-(95) is the sum of the support pressures of coal seam in $[-40, l] \mathrm{m}$ segment and the support resistance in $\left[l, l+L_{k}\right]$ segment in Figure 4 . The overlying loads of rock beam in $[-40, l+L] \mathrm{m}$ segment in Figure 4 are the same as the distributed load. Although the depths of the softened zone of coal seam $\left(l-l_{3}\right)$ in (93)-(95) are different, the sum of the support pressures of coal seam (or counterforce of coal seam) and the support resistance under the same rock beam load are very close.

In addition, the values of $\sum F_{y \text { above }}$ and $\sum F_{y \text { below }}$ are close to each other. Thus, the high accuracy of selecting the peak values of the support pressure of coal seam $f_{c 3}=10.062068$, $10.387880,10.814946$ in (87) together with $l_{3}=10.5,10,9.5 \mathrm{~m}$ was again validated.

Concerning an elastic-softened two-zone support rock beam, the expression of overlying load is the same as that in (90), and that of the sum of loads is the same as that in (92). Because of the absence of a hardening zone in coal seam, the sum of the support pressures and resistances of the coal seam beneath the rock beam can be expressed as follows:

$$
\sum F_{\text {ybelow }}=\int_{-40}^{0} C y_{2}(x) \mathrm{d} x+\int_{0}^{l_{3}} C y_{21}(x) \mathrm{d} x
$$




$$
\begin{aligned}
& +\int_{l_{3}}^{l} f_{3}(x) \mathrm{d} x+p_{\mathrm{o}} \times L_{k} \\
& +\frac{\left(p_{k}-p_{\mathrm{o}}\right) L_{k}}{2}
\end{aligned}
$$

By substituting $f_{\mathrm{c} 3}=10.346857,10.674489,11.112275 \mathrm{MN} / \mathrm{m}$ into (88) and the above data into (92), the sum of the support pressures and resistances of the coal seam beneath the rock beam when the depth of the softened zone of coal seam is $\left(l-l_{3}\right)=7.5,8,8.5 \mathrm{~m}$ can be obtained as follows:

$$
\begin{aligned}
\sum F_{y \text { below }}^{l_{3}=10.5}= & (30.490+8.2003+6.1641+0.396) \\
& \times 10^{7} \mathrm{~N}=45.2504 \times 10^{7} \mathrm{~N} \\
\sum F_{y \text { below }}^{l_{3}=10}= & (30.388+7.9898+6.4762+0.396) \\
& \times 10^{7} \mathrm{~N}=45.25 \times 10^{7} \mathrm{~N} \\
\sum F_{y \text { below }}^{l_{3}=9.5}= & (30.261+7.8071+6.7845+.396) \\
& \times 10^{7} \mathrm{~N}=45.2486 \times 10^{7} \mathrm{~N}
\end{aligned}
$$

The relative error between $\sum F_{y \text { below }}$ in (97)-(99) and $\sum F_{\text {yabove }}$ in (92) is less than 2/1000 0. Specifically, the relative errors in (97) and (93), (98) and (94), and (99) and (95) are below 3/1000 00, i.e., for the same depth of softened zone, the relative error between the sum of the support pressures (counterpressures) of the coal seam with threezone relationship and that with two-zone relationship is less than $3 / 100000$. This is because although the peak values of the support pressure $f_{c 3}$ of the elastic-softened two-zone relationship are slightly higher, the parts ahead of peaks on the support pressure curves of elastic-hardened-softened three-zone relationship are plumper, resulting in an identical area enveloped by support pressure curves of $[-40, l] \mathrm{m}$ segment.

\section{Conclusions}

(1) Based on the distribution pattern of measured support pressure and considering the hardening effect of coal seam, the support pressure relationship of three zones-softened, hardened, and elastic-for a coal seam and hard roof is proposed, and the methods for determining the approximate expressions for the support pressure of the hardened zone of a coal seam, the range of hardened zone, and the corresponding maximum support pressure are presented.

(2) By measuring the deflection curves of rock beam, all the selected three peak values of support pressure $f_{\mathrm{c} 3}$ in (84) were shown to satisfy the requirement of continuity of counterforce (support pressure) on rock beam at the junction between the elastic and hardened zones of coal seam.

(3) As the working face advances and the hanging roof distance $L$ increases (the total load above the corresponding coal seam increases), the peak values of the support pressure $f_{\mathrm{c} 3}$ of a coal seam gradually increase and the residual strengths $f_{3}(l)$ of a coal seam at the coal wall decrease, similar to the trend of moving support pressure shown in Figure 2. As the hanging roof distance increases, the overall deflection of rock beam slowly increases, the peak values of the bending moment of rock beam ahead of the coal wall increase, and the advanced distance of bending moment peak slowly increases, and the peak values of the bending moment of rock beam ahead of the coal wall are always higher than the absolute value of the bending moment of rock beam at the midspan of goaf in this phase.

(4) With the increase in the depth of a softened zone ( $l-$ $l_{3}$ ) of coal seam, the peak values of support pressure $f_{\mathrm{c} 3}$ of coal seam increase, the residual strengths of coal seam at the coal wall gradually decrease, the peak values of the bending moment of rock beam ahead of the coal wall increase, and the advanced distance of the bending moment peak of rock beam increases at a relatively fast rate. The bending moment peaks of roof are located near the support pressure peaks in the softened zone coal seam shown in Figures 15 and 18. The depth of the softened zone of coal seam significantly affects the advanced distance of the bending moment peak of hard roof.

(5) The advanced distance of bending moment peak is directly associated with the advanced fracturing distance of a hard roof. The advanced fracturing distances of hard roof that occur in a stope are distributed in a relatively broad range. The results in (3) indicate a "large and long" type advanced fracturing distance occurring in a stope.

(6) With identical stope parameter conditions, the peak values of the support pressure of a softened-hardened-elastic three-zone support roof are smaller than those of a softenedelastic two-zone support roof. However, the plumpness ahead of the support pressure curve peak of the former is better than that of the latter, and the peak values of bending moment and the advanced distances of bending moment peak of the former are higher than the corresponding peak values of the latter. The degree of superiority is related to the parameter $x_{\mathrm{c} 4}$ of the hardened zone of a coal seam.

\section{Data Availability}

The data used to support the findings of this study are available from the corresponding author upon request.

\section{Conflicts of Interest}

The authors declare that they have no conflicts of interest.

\section{Acknowledgments}

This work was supported by the Shandong Provincial Natural Science Foundation, China (ZR2018MEE009), the State Key Research Development Program of China (2016YFC0801403), and the Scientific Research Foundation of Shandong University of Science and Technology for Recruited Talents (2017RCJJ012). 


\section{References}

[1] Z. G. Wu, M. H. Zhai, and T. Z. Zhou, "Prediction to roof pressure of the west mine in Xuzhou," Chinese Journal of Rock Mechanics and Engineering, vol. 15, no. 2, pp. 163-170, 1996.

[2] Y. L. Tan, X. S. Liu, J. G. Ning, and Y. W. Lu, "In situ investigations on failure evolution of overlying strata induced by mining multiple coal seams," Geotechnical Testing Journal, vol. 40, no. 2, pp. 244-257, 2017.

[3] Y. L. Tan, F. H. Yu, J. G. Ning, and T. B. Zhao, "Design and construction of entry retaining wall along a gob side under hard roof stratum," International Journal of Rock Mechanics and Mining Sciences, vol. 77, pp. 115-121, 2015.

[4] W. Huang, Q. Yuan, Y. Tan et al., "An innovative support technology employing a concrete-filled steel tubular structure for a 1000-m-deep roadway in a high in situ stress field," Tunnelling and Underground Space Technology, vol. 73, pp. 2636, 2018.

[5] S.-C. Hu, Y.-L. Tan, H. Zhou et al., "Impact of bedding planes on mechanical properties of sandstone," Rock Mechanics and Rock Engineering, vol. 50, no. 8, pp. 2243-2251, 2017.

[6] X. S. Liu, J. G. Ning, Y. L. Tan, and Q. H. Gu, "Damage constitutive model based on energy dissipation for intact rock subjected to cyclic loading," International Journal of Rock Mechanics and Mining Sciences, vol. 85, pp. 27-32, 2016.

[7] J. Ning, J. Wang, Y. Tan, L. Zhang, and T. Bu, "In situ investigations into mining-induced overburden failures in close multiple-seam longwall mining: A case study," Geomechanics and Engineering, vol. 12, no. 4, pp. 657-673, 2017.

[8] J. Ning, J. Wang, J. Jiang, S. Hu, L. Jiang, and X. Liu, "Estimation of crack initiation and propagation thresholds of confined brittle coal specimens based on energy dissipation theory," Rock Mechanics and Rock Engineering, vol. 51, no. 1, pp. 119-134, 2017.

[9] T. Zhao, W. Guo, Y. Tan, C. Lu, and C. Wang, "Case histories of rock bursts under complicated geological conditions," Bulletin of Engineering Geology and the Environment, pp. 1-17, 2017.

[10] J. Xu and J. Ju, "Structural morphology of key stratum and its influence on strata behaviors in fully-mechanized face with super-large mining height," Chinese Journal of Rock Mechanics and Engineering, vol. 30, no. 8, pp. 1547-1556, 2011.

[11] T. Zhao, W. Guo, Y. Tan, Y. Yin, L. Cai, and J. Pan, "Case studies of rock bursts under complicated geological conditions during multi-seam mining at a depth of $800 \mathrm{~m}$," Rock Mechanics and Rock Engineering, vol. 51, no. 5, pp. 1539-1564, 2018.

[12] D. Ma, M. Rezania, H.-S. Yu, and H.-B. Bai, "Variations of hydraulic properties of granular sandstones during water inrush: effect of small particle migration," Engineering Geology, vol. 217, pp. 61-70, 2017.

[13] D. Ma, X. Cai, Z. Zhou, and X. Li, "Experimental investigation on hydraulic properties of granular sandstone and mudstone mixtures," Geofluids, vol. 2018, Article ID 9216578, 13 pages, 2018.

[14] Z. Zhou, X. Cai, D. Ma, W. Cao, L. Chen, and J. Zhou, "Effects of water content on fracture and mechanical behavior of sandstone with a low clay mineral content," Engineering Fracture Mechanics, vol. 193, no. 15, pp. 47-65, 2018.

[15] M. G. Qian, X. B. Mao, and X. X. Miao, "Variation of loads on the key layer of the overlying strata above the working," Journal of China Coal Society, vol. 23, no. 2, pp. 135-139, 1998.

[16] M. G. Qian, J. S. Yin, and S. Y. Liu, "Immediate roof caving in, tip to face, area of fully mechanized longwall face," Journal of China Coal Society, vol. 15, no. 1, pp. 1-9, 1990.
[17] X. X. Miao, X. B. Mao, and T. Z. Zhou, "Elastic foundation structure analysis of stope main roof and weighting forecast," Mechanics in Engineering, pp. 21-22,41, 1995.

[18] X. Y. Li, N. J. Ma, Y. P. Zhong, and Q. C. Gao, "Storage and release regular of elastic energy distribution in tight roof fracture," Chinese Journal of Rock Mechanics and Engineering, vol. 26, supplement 1, pp. 2786-2793, 2007.

[19] S. Peng Syd, Coal Mine Ground Control, China University of Mining and Technology Press, Xuzhou, China, 2013.

[20] Y. Pan and S. T. Gu, "Analysis on mechanics property of hard roof influenced by plastic zone of coal seam," Chinese Journal of Rock Mechanics and Engineering, vol. 34, no. 12, pp. 2486-2499, 2015.

[21] G. Y. Shao, L. Kan, H. F. Ma, and S. L. Wu, "Distribution characteristics of abutment force in fully mechanized working face," Modern Mining, vol. 10, pp. 84-85, 2011.

[22] M. C. He, H. H. Jin, and X. M. Sun, Engineering Mechanics of Soft Rock, Science Press, Beijing, China, 2002.

[23] G. Z. Shao, "Advanced fracture of and forecast of weighting," Ground Pressure and Strata Control, vol. 6, no. 2, pp. 59-64, 1989.

[24] Y. L. Tan and X. S. Wang, "A preliminary study of acoustic emission of rock weighing process in a coal mine," Chinese Journal of Rock Mechanics and Engineering, vol. 11, no. 3, pp. 274-283, 1992

[25] Y. L. Tan and Y. J. Yang, "Discussion of anti-elasticity and its engineering significance," Mechanic and Engerniring, vol. 18, no. 2, pp. 21-23, 1996.

[26] X. R. Wu and M. T. Yang, "Fracture and the first caving in hard and massive overlying strata," Ground Pressure and Strata Control, vol. 7, no. 2, pp. 22-25, 1990.

[27] S. Timoshenko, Strength of Materials, Science Press, Beijing, China, 1979. 


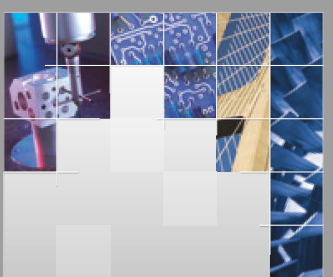

\section{Enfincering}
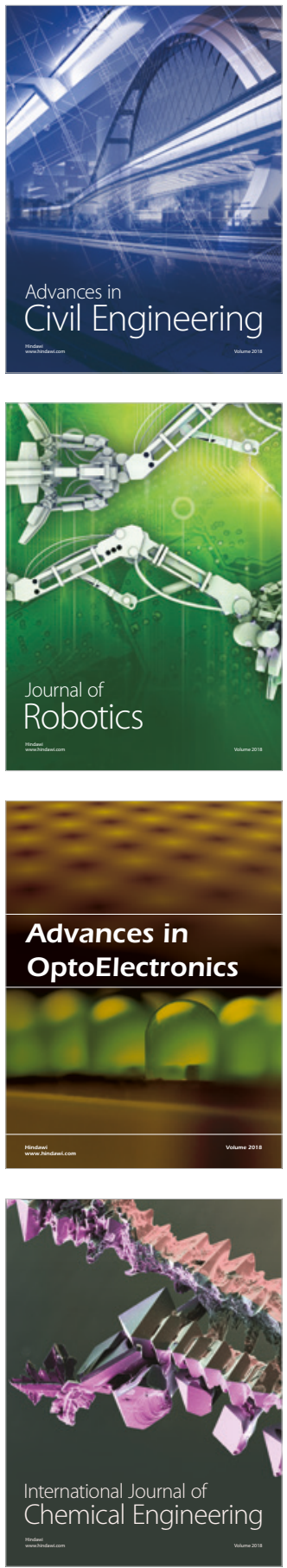

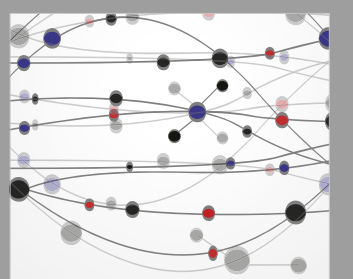

\section{Rotating \\ Machinery}

The Scientific World Journal

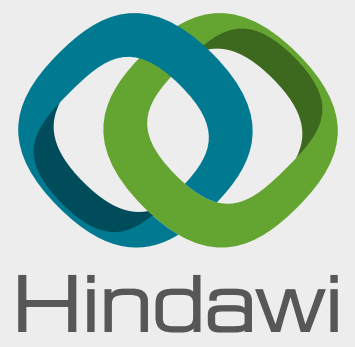

Submit your manuscripts at

www.hindawi.com
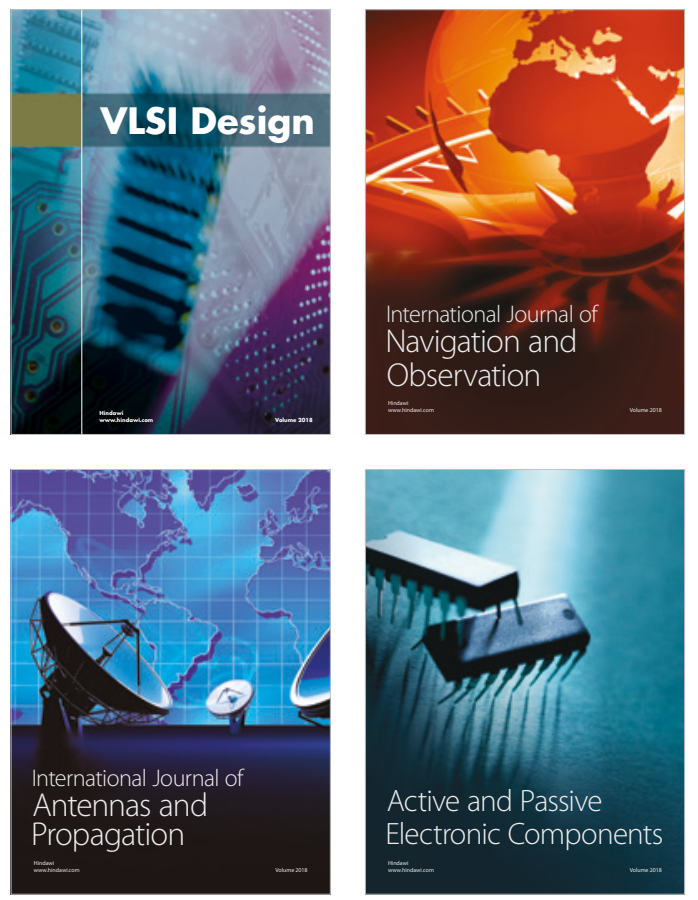
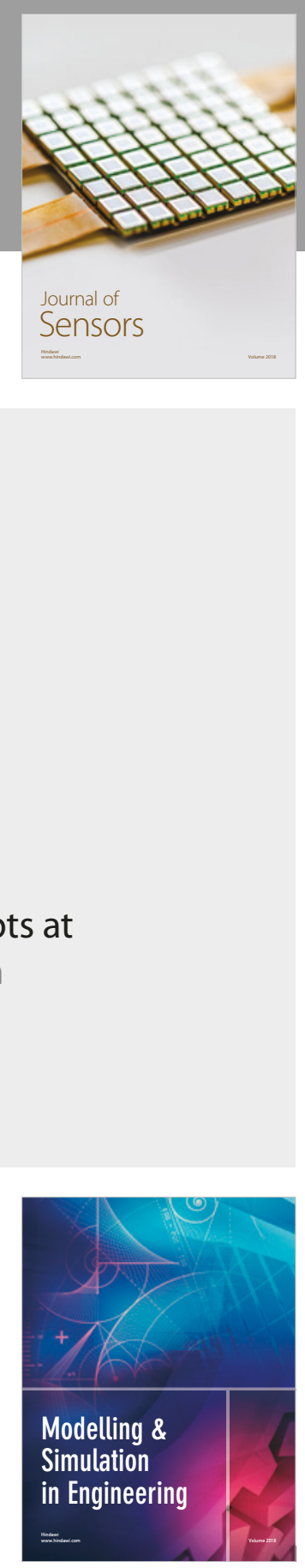

\section{Advances \\ Multimedia}
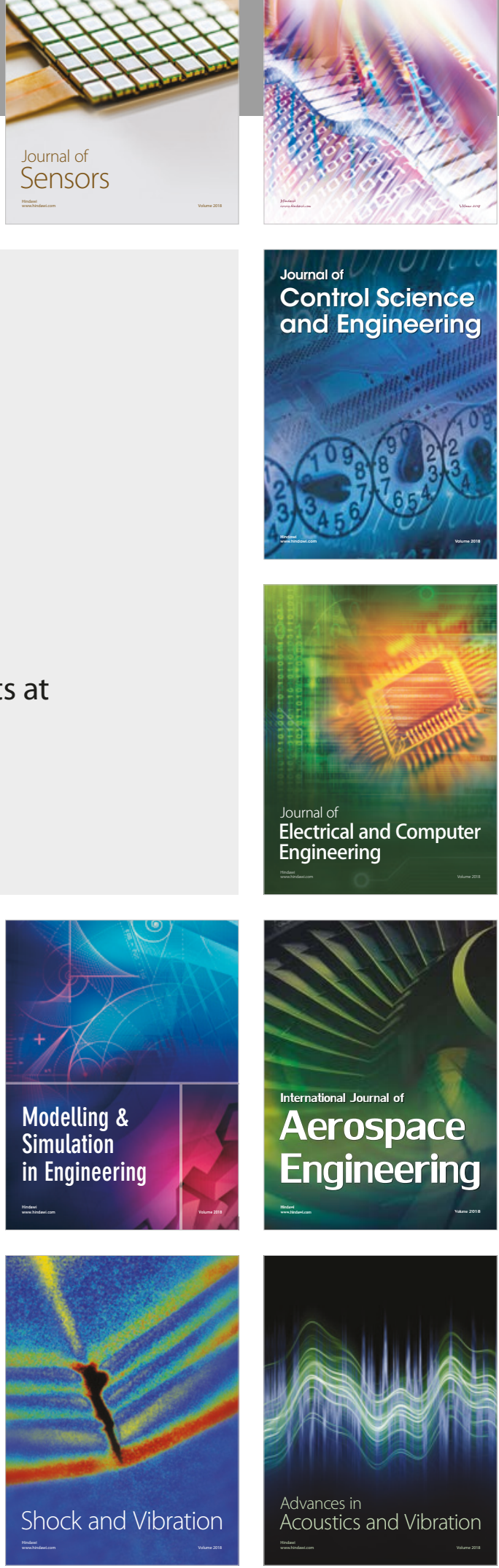